\title{
Renal Association Clinical Practice Guideline on Detection, Monitoring and Management of Patients with CKD
}

\author{
Dr Mark S. MacGregor ${ }^{\mathrm{a}}$ and Dr Maarten W. Taal ${ }^{\mathrm{b}}$ \\ ${ }^{a}$ Consultant Nephrologist, Crosshouse Hospital, Kilmarnock \\ ${ }^{b}$ Consultant Nephrologist, Derby Hospitals NHS Foundation Trust, Derby
}

\section{Key Words}

chronic kidney disease - detection - monitoring - treatment · urinalysis - proteinuria - estimated GFR - hypertension dyslipidaemia - angiotensin converting enzyme inhibitors . angiotensin receptor blockers

\section{Introduction}

As was the case with the first version of these guidelines for the detection, monitoring and care of patients with CKD, published in 2007, this update follows the publication of National Guidelines applicable to England and Wales (National Institute for Health and Clinical Excellence, NICE) [1], and Scotland (Scottish Intercollegiate Guidelines Network, SIGN) [2]. This situation has produced for us as authors both advantages and challenges. On the one hand we have been able to draw on the comprehensive reviews of published evidence

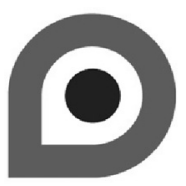

NHS Evidence Accreditation Mark presented in the NICE and SIGN guidelines. Given this situation, we have not attempted to duplicate the excellent work already done by these guideline development groups and will present only a brief rationale for each guideline, rather than an exhaustive review of the literature. On the other hand, we face the challenge of producing a guideline that is compatible with both National Guidelines despite minor differences between them. In an effort to produce unified guidance applicable to all members of the Renal Association, we have attempted to phrase all guideline statements to be compatible with both the NICE and SIGN guidance.

Given the recent publication of two comprehensive national guidelines, it could be argued that further UK Guidelines were unnecessary. We would argue that a unique feature of these guidelines is that they are deliberately concise and that they include suggested audit measures. This emphasis is intended to drive real operational improvement in the way that patients with CKD are managed. As such it is intended that these guidelines be applicable to all patients with $\mathrm{CKD}$, whether managed

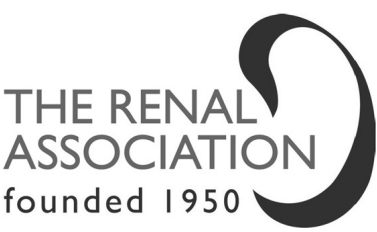

Dr Mark S. MacGregor and Dr Maarten W. Taal Email: Mark.MacGregor@aaaht.scot.nhs.uk and Maarten.Taal@derbyshirehospitals.nhs.uk
(C) $2011 \mathrm{~S}$. Karger AG, Basel

1160-2110/11/1185-00071\$38.00/0

Accessible online at: www.karger.com/nec 
in a Primary or Secondary Care setting. We recognise, however, that not all of the suggested audit measures will be relevant in every setting. Rather, we offer the audit measures as a 'menu' of possible measures from which health care workers may select those relevant to their service.

We have largely preserved the structure of the previous CKD guidelines, published in 2007, but have added some additional guideline statements to reflect changes in practice and new published evidence. In accordance with Clinical Practice Guideline Committee policy, we have used the internationally recognised modified GRADE system to define the strength of each guideline

\section{References}

1 National Institute for Health and Clinical Excellence (NICE): Chronic Kidney Disease. National clinical guideline for early identification and management in adults in primary and secondary care. 2008 statement and the quality of the evidence to support it. The rationale section for each statement has been updated to reflect recent published data. Section 3 (Preparation for Dialysis) has been removed as it is now dealt with in other sections of the Clinical Practice Guidelines. We hope that these updated guidelines will contribute, together with several other excellent measures including National Service Framework for Renal Services, Quality and Outcomes Framework of the General Medical Services (GMS) contract for General Practitioners (in England and Wales) and the National Guidelines, to promote the provision of excellent care to all patients with CKD.

2 Scottish Intercollegiate Guidelines Network (SIGN): Diagnosis and management of chronic kidney disease: A national clinical guideline. 2008 


\section{Summary of Clinical Practice Guidelines for Detection, Monitoring and Care of CKD}

\section{Chronic Kidney Disease (CKD) (Guidelines CKD} 1.1-1.12)

\section{Guideline 1.1 - CKD: Detection and Monitoring of CKD}

We recommend that amongst patients with CKD (excluding those on long term dialysis), each measurement of serum creatinine concentration in a database or clinic letter should be accompanied by an estimate of GFR. (1B)

\section{Guideline 1.2 - CKD: Detection and Monitoring of CKD}

We recommend that the stage of $\mathrm{CKD}$, as defined by the US K/DOQI classification with the modifications recommended by NICE and/or SIGN, should be noted in the patient records at each clinic visit and communicated in any letters generated. (1C)

\section{Guideline 1.3 - CKD: Detection and Monitoring of CKD}

We recommend that in patients being investigated or treated for CKD, proteinuria should be assessed by measurement either of the protein to creatinine or albumin to creatinine ratio, ideally on an early-morning urine specimen. (1A)

Guideline 1.4 - CKD: Detection and Monitoring of CKD

We recommend that patients who are at increased risk for developing CKD should be offered screening tests to detect CKD. (1B)

\section{Guideline 1.5 - CKD: Detection and Monitoring of CKD}

We recommend that screening for $\mathrm{CKD}$ should comprise assessment of the estimated GFR as well as urinalysis. (1A)

\section{Guideline 1.6 - CKD: Detection and Monitoring of CKD}

We recommend that detection of an initial abnormal estimated GFR result should prompt clinical assessment and a repeat test within 2 weeks to assess the rate of change in GFR. If the GFR is stable, a further test should be performed after 90 days to confirm the diagnosis of CKD. If the diagnosis of CKD is confirmed at least 3 assessments of estimated GFR should be made over not less than 90 days to evaluate the rate of change in GFR. (1D)

\section{Guideline 1.7 - CKD: Detection and Monitoring of CKD}

We recommend that detection of an initial level of proteinuria equivalent to $<0.5 \mathrm{~g} /$ day of total protein (including levels compatible with microalbuminuria) should be confirmed with a repeat test performed on an early morning urine specimen. For the diagnosis of microalbuminuria 2 abnormal results from 3 specimens are required. (1B)

\section{Guideline 1.8 - CKD: Detection and Monitoring of CKD}

We recommend that patients in whom initial urinalysis reveals non-visible/microscopic haematuria should have a urine culture performed to exclude a urinary tract infection. If a UTI is excluded two further tests should be performed to confirm the presence of persistent non-visible/microscopic haematuria. Patients $>40$ years of age with persistent non-visible/microscopic haematuria in the absence of significant proteinuria or a reduced GFR should be referred to a Urology Department for further investigation. (1D)

\section{Guideline 1.9 - CKD: Detection and Monitoring of CKD}

We recommend that among patients with $\mathrm{CKD}$, the estimated GFR should be monitored regularly. (1B)

\section{Guideline 1.10 - CKD: Detection and Monitoring of CKD}

We recommend that patients with CKD should have the magnitude of their proteinuria assessed at least annually. (1C)

\section{Guideline 1.11 - CKD: Detection and Monitoring of CKD}

We recommend that Nephrology Units should negotiate service agreements for the detection and monitoring of CKD, including criteria for referral to a Nephrologist. (1D)

\section{Guideline 1.12 - CKD: Detection and Monitoring of CKD}

We recommend that a Nephrology Unit should establish an easily accessible non-visit-based Specialist advice service for Primary Care Physicians. (1D) 
2. Chronic Kidney Disease (CKD) (Guidelines CKD 2.1-2.13)

\section{Guideline 2.1 - CKD: Treatment of patients with CKD}

We recommend that in patients with $\mathrm{CKD}$, systolic blood pressure should be lowered to $<140 \mathrm{mmHg}$ (target range $120-139 \mathrm{mmHg}$ ) and the diastolic blood pressure to $<90 \mathrm{mmHg}$ for the majority. For those with diabetes mellitus or proteinuria of $1 \mathrm{~g} / 24$ hours or greater, the systolic blood pressure should be lowered to $<130 \mathrm{mmHg}$ (target range $120-129 \mathrm{mmHg}$ ) and the diastolic blood pressure to $<80 \mathrm{mmHg}$ unless the risks are considered to outweigh the potential benefits. Antihypertensive therapy should be individualised and lowering the systolic blood pressure to $<120 \mathrm{mmHg}$ should be avoided. (1B)

\section{Guideline 2.2-CKD: Treatment of patients with CKD}

We recommend that Angiotensin-Converting Enzyme Inhibitor (ACEI) or Angiotensin Receptor Blocker (ARB) treatment should form part of the antihypertensive therapy of patients with CKD and urinary protein excretion of $>0.5 \mathrm{~g} /$ day unless there is a specific contraindication. (1A)

\section{Guideline 2.3 - CKD: Treatment of patients with CKD}

We suggest that patients with $\mathrm{CKD}$ and proteinuria $>0.5 \mathrm{~g} /$ day should have their ACEI or ARB and other antihypertensive treatment escalated to achieve the lowest possible level of proteinuria. (2C)

\section{Guideline 2.4 - CKD: Treatment of patients with CKD}

We recommend that patients with diabetes mellitus and microalbuminuria should be treated with an ACEI or ARB, titrated to maximum licensed antihypertensive dose if tolerated, regardless of the initial blood pressure, unless these drugs are specifically contraindicated. Hypotension should be avoided. (1A)

\section{Guideline 2.5 - CKD: Treatment of patients with CKD}

We recommend that patients with diabetes mellitus and CKD should achieve good glycaemic control. (1B)
Guideline 2.6-CKD: Treatment of patients with CKD

We recommend that patients with CKD should have an annual formal assessment of their cardiovascular risk factors including lipid profile, BMI, exercise, alcohol and smoking habits as well as a review of interventions to reduce cardiovascular risk. (1D)

\section{Guideline 2.7 - CKD: Treatment of patients with CKD}

We recommend that patients with CKD and dyslipidaemia should be treated in accordance with current guidance for the general population. (1C)

\section{Guideline 2.8 - CKD: Treatment of patients with CKD}

We suggest that smoking status and action taken should be documented in the patient record at each nephrology clinic visit. (1D)

\section{Guideline 2.9-CKD: Treatment of patients with CKD}

We suggest that patients with CKD and a BMI of $>30 \mathrm{~kg} / \mathrm{m}^{2}$ should receive dietary advice to assist them in losing weight. (2D)

\section{Guideline 2.10 - CKD: Treatment of patients with CKD}

We recommend that patients with CKD should receive dietary advice to restrict their sodium intake to $<2.4 \mathrm{~g} /$ day $(100 \mathrm{mmol} /$ day or $<6 \mathrm{~g} /$ day of salt). (1B)

\section{Guideline 2.11 - CKD: Treatment of patients with CKD}

We recommend that patients with CKD who develop hyperkalaemia or hyperphosphataemia should receive dietary advice to assist dietary restriction of potassium and phosphate. (1C)

\section{Guideline 2.12 - CKD: Treatment of patients with CKD}

We suggest that patients with CKD should receive advice to perform regular moderate exercise. (2D)

\section{Guideline 2.13-CKD: Treatment of patients with CKD}

We recommend that patients with CKD should be referred for assessment by a Nephrology Department according to the NICE Guidelines. (1B) 
Summary of audit measures for detection, monitoring and management of CKD

1. Proportion of database entries or clinic letters related to patients with $\mathrm{CKD}$ that include an estimated GFR with the serum creatinine.

2. Proportion of patient record entries and clinic letters that include the modified K/DOQI CKD stage.

3. Proportion of CKD patients who had a urine protein or albumin to creatinine ratio measured at their first clinic visit.

4. Proportion of patients with significant risk factors for CKD who have been screened for CKD.

5. Proportion of patients screened for CKD who have had (a) an assessment of estimated GFR, (b) urinalysis, (c) both an assessment of estimated GFR and urinalysis.

6. Proportion of initial abnormal estimated GFR results that are followed by a repeat test within 2 weeks and a further test at 90 days (where appropriate).

7. Proportion of patients with CKD stage 3 or worse in whom the diagnosis has been confirmed by two estimated GFR readings, at least 90 days apart.

8. Proportion of patients with a confirmed diagnosis of CKD in whom the rate of change in GFR has been evaluated with at least 3 assessments of GFR over not less than 90 days.

9. Proportion of patients with proteinuria equivalent to $<0.5 \mathrm{~g} /$ day in whom the result has been confirmed with a repeat test performed on an early morning urine specimen.

10. Proportion of patients with a diagnosis of microalbuminuria in whom the diagnosis has been confirmed with at least 2 abnormal results.

11. Proportion of patients with initial detection of non-visible/microscopic haematuria with a urine culture result.

12. Proportion of patients with non-visible/microscopic haematuria in whom the result was confirmed with a total of at least 3 tests.

13. Proportion of patients with persistent nonvisible/microscopic haematuria in the absence of significant proteinuria or a reduced GFR that were referred to a Urology Department.

14. Proportion of patients with CKD with regular monitoring of the estimated GFR at the frequency recommended by NICE or local guidelines.
15. Proportion of patients with CKD who have had a measurement of proteinuria within the previous 12 months.

16. Proportion of Nephrology Units with specific service agreements for the detection and monitoring of CKD within a defined organisational area.

17. Proportion of all new outpatient attendances that could have been avoided by appropriate nonvisit-based specialist advice.

18. Number of requests for non-visit-based advice relative to the total number of referrals per month.

19. Proportion of patients with CKD and follow-up for at least 6 months, whose last recorded blood pressure was within the target range specified above unless specifically contraindicated.

20. Proportion of patients with CKD and hypertension, followed up for at least 6 months, with a systolic blood pressure $<120 \mathrm{mmHg}$ in the absence of cardiac failure.

21. Proportion of proteinuric CKD patients (as defined above) without contraindications who have an ACEI or ARB on their last recorded list of chronic medications.

22. Proportion of patients with CKD and proteinuria who achieve a decrease in proteinuria to $<0.5 \mathrm{~g} /$ day.

23. Proportion of patients with diabetes mellitus and microalbuminuria (without specific contraindications) who had an ACEI or ARB on their last recorded list of chronic medications.

24. Proportion of patients receiving an ACEI or ARB for diabetes and microalbuminuria who received the maximum licensed antihypertensive dose (or maximum dose tolerated without hypotension) on their most recent prescription.

25. Proportion of patients with diabetic nephropathy and follow-up for at least 6 months, whose last recorded $\mathrm{HBA}_{1 \mathrm{C}}$ was below their agreed target.

26. Average $\mathrm{HBA}_{1 \mathrm{C}}$ of all patients with diabetes mellitus and CKD.

27. Proportion of CKD patients with a formal assessment of cardiovascular risk factors documented in their records during the past year.

28. Proportion of CKD patients with indications for lipid lowering therapy as defined by NICE/JBS 2 .

29. Proportion of CKD patients with indications for lipid lowering therapy as defined by NICE/JBS 2 , who are receiving lipid lowering therapy. 
30. Proportion of CKD patients who currently do not have an indication for lipid lowering therapy as defined by NICE/JBS 2 but who are receiving a lipid lowering agent.

31. Proportion of CKD patients with smoking status recorded in their last record entry.

32. Proportion of CKD patients who are current smokers that received an offer of assistance with smoking cessation during the past year of follow-up.

33. Proportion of smoking CKD patients who ceased smoking during the past year.

34. Proportion of patients with CKD and obesity who have received dietary advice to assist weight loss.

35. Proportion of patients with CKD who have received dietary advice to assist dietary sodium restriction.

36. Proportion of patients with CKD stages 4 and 5 who have received dietary advice to assist dietary restriction of potassium and phosphate.
37. Proportion of patients with CKD stages $1-3$ and hyperkalaemia or hyperphosphataemia who have received dietary advice to assist dietary restriction of potassium and phosphate.

38. Proportion of patients with CKD who have received advice to undertake regular exercise.

39. Proportion of patients with CKD who report performing regular moderate exercise.

40. Proportion of patients on Primary Care CKD registers who have been referred to a Nephrology Department.

41. Proportion of patients on Primary Care CKD registers with an indication for referral to a Nephrology Department.

42. Proportion of patients on Primary Care CKD registers with an indication for referral who have been referred to a Nephrology Department. 


\section{Rationale of Clinical Practice Guidelines for Detection, Monitoring and Management of CKD}

\section{Chronic Kidney Disease (CKD) (Guidelines CKD 1.1-1.12)}

\section{Guideline 1.1 - CKD: Detection and Monitoring of CKD}

We recommend that amongst patients with CKD (excluding those on long term dialysis), each measurement of serum creatinine concentration in a database or clinic letter should be accompanied by an estimate of GFR. (1B)

\section{Audit measure}

Proportion of database entries or clinic letters related to patients with CKD that include an estimated GFR with the serum creatinine

\section{Rationale}

Renal excretory function has in the past generally been assessed by means of serum creatinine concentration and creatinine clearance measurements. Serum creatinine alone is a poor measure of excretory function because its relationship with GFR is non-linear and it rises outside of the laboratory normal range only after substantial loss of renal function. Moreover there is substantial interlaboratory variation in serum creatinine values, depending on the method used. The Cockcroft-Gault (CG) formula has been used to estimate creatinine clearance from serum creatinine concentration but has the disadvantage of requiring the patient's weight, which is usually not available to laboratories. Creatinine clearance is critically dependent on an accurate 24-hour urine collection, which many patients find difficult and inconvenient to achieve. The 4 -variable MDRD equation was developed from data obtained from a large cohort of patients with CKD who had had excretory function assessed by ${ }^{125}$ I-iothalamate clearance [1]. The MDRD formula is more precise than the CG formula [2] and its main advantage is that it requires, in addition to the serum creatinine, only the age, gender and ethnicity of the patient, variables that are usually available in the laboratory database. This in turn has made it possible for laboratories to report automatically an estimated GFR value with each serum creatinine result. Several international guidelines (including KDOQI, CARI and KDIGO) recommend that an estimated GFR derived from the 4-variable MDRD equation should be reported with each serum creatinine measurement. Similarly, the
NICE and SIGN guidelines each recommend reporting of estimated GFR derived from a prediction equation $[3,4]$. Interlaboratory variation in creatinine results has been addressed through standardisation of serum creatinine results to an isotope dilution mass spectrometry (IDMS) method by the National External Quality Assurance Scheme. A modification of the MDRD formula has been developed for use with IDMS standardised serum creatinine values [5]. The Department of Health for England has endorsed the use of the IDMStraceable simplified MDRD formula by all clinical biochemistry laboratories. Due to the fact that each laboratory applies a correction factor specific to its creatinine assay, clinicians should rely on laboratorygenerated estimates of GFR, rather than calculating them directly using a formula or 'GFR calculator'. Owing to the underestimation of GFR at values close to normal, many laboratories have chosen not to report a specific value if it is $>60 \mathrm{ml} / \mathrm{min} / 1.73 \mathrm{~m}^{2}$. This approach has been endorsed by both the NICE and SIGN guidance $[3,4]$.

The adoption of the MDRD formula for universal laboratory-based estimation of GFR, and of the 5-stage classification of CKD based on these estimates, has been controversial on several grounds. Even after adequate correction has been made for overestimation of serum creatinine in some assays, the formula is not perfect, and its use can result in misclassification of some people as having early stage $3 \mathrm{CKD}$, due to systematic underestimation of 'true' GFR $[2,6]$ and imprecision, particularly when the GFR is $>60 \mathrm{ml} / \mathrm{min} / 1.73 \mathrm{~m}^{2}$. The formula has not been well validated in the very old, or in ethnic minority groups other than African-Americans. Its use is not valid in children, pregnant women, people at the extremes of body size [2], muscle mass or nutritional status, or in patients with acute kidney injury [7]. Reduced GFR is common amongst the elderly, leading some to argue that this is not a disease state but part of normal ageing. The division of CKD into five bands based on GFR is seen by some as arbitrary. Concerns have been expressed that inappropriate 'disease labelling' of people newly informed that they have CKD will lead to anxiety and to adverse changes in illness behaviour [8]. Some see the introduction of laboratory-based eGFR reporting as a form of screening, and argue that the case for screening the population for CKD has not been adequately supported by evidence [9]. Others have argued, however, that if doctors request a measurement of serum creatinine they are requesting an estimate of kidney function, and that the eGFR provides a much better estimate [10]. 
Furthermore eGFR is a powerful predictor of cardiovascular risk and of progressive CKD, reduced GFR is not an inevitable consequence of ageing and the great majority of people newly recognised as having CKD already have diagnoses of vascular disease, hypertension, or diabetes mellitus. These arguments have been rehearsed in depth elsewhere [9-13]. We take the view that the advantages of the simple classification system adopted in the UK (and elsewhere in the world) greatly outweigh the potential disadvantages. The advantages include simplicity (estimated GFR approximates percentage of normal kidney function), and the opportunities both for improved prevention of cardiovascular disease and for systematic reduction in the late referral of patients with established renal failure.

In order to address some of the limitations of the MDRD equation, a new equation for estimating GFR from serum creatinine has been developed by the Chronic Kidney Disease Epidemiology (CKD-EPI) collaboration [14]. Data from 10 studies that had measured GFR using filtration markers (mostly iothalomate) were used and divided into separate datasets for the development and internal validation of the equation. The CKD-EPI equation performed better than the MDRD equation, particularly at higher GFR values. The CKD-EPI equation evidenced less bias, greater accuracy and improved precision. Nevertheless, the authors concede that the study population included relatively few elderly subjects or subjects from ethnic minorities. To date the CKD-EPI equation has not yet been widely adopted but if further validation studies confirm these initial findings it is possible that it will replace the MDRD equation as the preferred method for estimating GFR.

\section{Guideline 1.2 - CKD: Detection and Monitoring of CKD}

We recommend that the stage of CKD, as defined by the US K/DOQI classification with the modifications recommended by NICE and/or SIGN, should be noted in the patient records at each clinic visit and communicated in any letters generated. (1C)

\section{Audit measure}

Proportion of patient record entries and clinic letters that include the modified K/DOQI CKD stage

\section{Rationale}

In 2002 National Kidney Foundation Kidney Disease Outcomes Quality Initiative (K/DOQI) proposed a classification system for CKD based on GFR [15]. This provides a useful framework for studying the prevalence and incidence of CKD in epidemiological studies but more importantly, facilitates the development of treatment guidelines and management plans based on disease severity. The K/DOQI classification has been adopted world wide and endorsed by a large number of national and international professional organisations $[16,17]$. On the other hand, others have called for a complete overhaul of the classification system because the GFR bands are considered arbitrary, it ignores variation in GFR due to age, gender and ethnicity and leads to overdiagnosis of CKD [13]. Following the recommendation of a UK Consensus Conference on early CKD [18], the NICE and SIGN guidelines recommended that the K/DOQI classification should be modified by dividing CKD stage 3 into CKD $3 \mathrm{~A}$ and $3 \mathrm{~B}$ and that a suffix ' $\mathrm{p}$ ' should be used for all stages to denote patients with significant proteinuria (equivalent to $\geqslant 0.5 \mathrm{~g} /$ day in the NICE guideline or $\geqslant 1 \mathrm{~g}$ /day in the SIGN guideline), who are at increased risk for progression [3, 4]. This goes some way to answering the objections of those opposed to the K/DOQI classification system and we recommend it should continue to be incorporated into treatment guidelines for CKD and reported in all written communication. Letters from Nephrology Departments to Primary Care should also include information on sources of further information regarding the 5-stage classification of CKD such as links to intranet and internet sites.

\section{Guideline 1.3 - CKD: Detection and Monitoring of CKD}

We recommend that in patients being investigated or treated for CKD, proteinuria should be assessed by measurement either of the protein to creatinine or albumin to creatinine ratio, ideally on an early-morning urine specimen. (1A)

\section{Audit measure}

Proportion of CKD patients who had a urine protein or albumin to creatinine ratio measured at their first clinic visit

\section{Rationale}

Urine dipstick testing has in the past been used to screen patients with CKD for proteinuria. Both the NICE and SIGN guidelines oppose this because reagent strip tests are dependent on urine concentration and are unreliable for the detection of low levels of 
proteinuria or quantification of the proteinuria. The magnitude of urinary protein excretion has traditionally been assessed by means of a 24 -hour urine collection. If accurately performed this undoubtedly provides the most precise measurement of proteinuria but the clinical utility of 24-hour urine collections is limited by inconvenience to patients, inaccurate collections and the burden on laboratory staff having to process the specimens. Several studies have shown good correlations between the total protein or albumin to creatinine ratio on early morning spot urine sample and 24-hour urinary protein excretion [19-22]. Furthermore urine protein to creatinine ratio on a spot morning specimen has been shown to predict the risk of progression at least as reliably as 24-hour urinary protein excretion in CKD patients without diabetes [23] and urine albumin to creatinine ratio has been shown to predict renal outcomes better than $24 \mathrm{~h}$ urinary protein or albumin excretion in diabetic patients with CKD [24]. If the urine protein to creatinine ratio is expressed in $\mathrm{mg} / \mathrm{mg}$ the value obtained is approximately the same as the number of grams/24 hours of urinary protein excretion. On the other hand if the ratio is expressed as $\mathrm{mg} / \mathrm{mmol}$, $24 \mathrm{~h}$ protein excretion is approximately 10 times this figure (based on an assumed average urinary creatinine excretion of $10 \mathrm{mmol} /$ day). It should be noted that agreement between urine protein:creatinine ratio and 24-hour protein may be reduced if proteinuria is in the nephrotic range [25] and that urine protein to creatinine ratio may be unreliable in patients with unusually large or small muscle mass because urinary creatinine excretion varies with muscle mass and this may affect the protein to creatinine ratio independent of urinary protein excretion [19]. It has been argued that spot urine protein to creatinine ratio measurements should not be used to assess proteinuria because they are subject to wide variations depending on the time of day they were obtained [26]. The counter-argument is that this variation can be minimised by using a specimen of early morning urine and that use of spot urine protein to creatinine ratio will promote more widespread monitoring of proteinuria as an important marker of prognosis in CKD $[23,24,27]$. A detailed discussion of the relative advantages and disadvantages of spot urine protein to creatinine ratio and 24-hour urine collections has previously been published [23, 26].

The decision on whether to measure urinary total protein or albumin will depend on clinical and local factors including cost (albumin is more expensive to assay than total protein). As urine may contain variable amounts of several different proteins, urine protein to creatinine ratio will generally be higher than albumin to creatinine by a variable amount [28]. Both measures provide useful prognostic information but there is no simple method for extrapolating from one to the other. The measurement of urinary albumin to detect the earliest stage of diabetic nephropathy, characterised by microalbuminuria, is already well established in clinical practice. Furthermore, several studies have identified urinary albumin excretion as a risk factor for progression to end-stage kidney disease (ESKD) $[29,30]$ and a large meta-analysis has found that urinary albumin to creatinine measurements are strongly predictive of cardiovascular and all cause mortality among cohorts drawn from the general population, independent of estimated GFR [31]. On the other hand urinary total protein measurements have been used to monitor the progression of CKD as well as the response to treatment in many of the major clinical trials that inform current renal protective strategies [32]. The NICE guidelines recommend the use of urine albumin to creatinine ratio for the initial detection of proteinuria and for all measurements in people with diabetes. Protein to creatinine ratio is considered an alternative for quantification and monitoring of proteinuria. The SIGN guidelines similarly recommend the use of urine albumin to creatinine ratio for detecting and monitoring diabetic nephropathy and state that urine protein to creatinine ratio may be used in patients without diabetes.

\section{Guideline 1.4 - CKD: Detection and Monitoring of CKD}

We recommend that patients who are at increased risk for developing CKD should be offered screening tests to detect CKD. (1B)

\section{Audit measure}

Proportion of patients with significant risk factors for CKD who have been screened for CKD

\section{Rationale}

In the UK, most patients with CKD are identified opportunistically, when blood, urine or imaging tests are performed for clinical indications. Although around two thirds of the adult population over 65 years old will have their eGFR measured in a single year [33], there remains a shortfall in CKD prevalence identified by the Quality Outcomes Framework (QOF) compared to epidemiological studies. Screening offers the opportunity to identify patients with CKD at an 
earlier stage of their disease, when interventions to reduce cardiovascular and renal risk might be more effective. Nevertheless, screening of the general population has not been recommended, because it is not thought to be cost-effective in the UK $[3,4]$, or in Canada [34]. The challenge is therefore to identify subpopulations at sufficient increased risk to warrant screening.

Annual screening has been recommended in various groups at increased risk of kidney disease. It is costeffective in patients with diabetes mellitus (by serum creatinine and urine albumin to creatinine ratio) [3, 34], and is also a quality indicator in the QOF. Annual screening has also been recommended for patients with high blood pressure [3], or patients receiving treatment with anti-hypertensives [34], though the supporting evidence is less strong than for diabetes mellitus. Annual screening has also been recommended for patients on treatment with lipid-lowering agents (as a marker of cardiovascular risk) [34]. Although evidence on the value of screening is limited, it is also recommended that patients receiving ongoing treatment with nephrotoxic drugs (e.g. calcineurin inhibitors, nonsteroidal anti-inflammatory drugs, lithium) should have annual monitoring of renal function [3]. Annual monitoring of eGFR in patients receiving lithium is also a quality indicator in the QOF.

Screening has been recommended for other groups, but without specifying the frequency [3]:

- individuals with a family history of stage 5 CKD or hereditary renal disease

- patients with vascular disease (ischaemic heart disease, chronic heart failure, peripheral arterial disease, cerebral vascular disease)

- patients with structural renal disease, renal calculi or prostatic hypertrophy

- patients with multisystem disease with potential renal involvement

The latter two are based on knowledge of pathophysiology and disease progression rather than published risk estimates.

Other groups of patients have increased risk of CKD, but have not had screening recommended, either because of doubt about the degree of additional risk, or lack of evidence of cost-effectiveness:

- Increasing age [35-38]

- First degree relative with high blood pressure, diabetes mellitus or CKD [39]
- Tobacco smoking (>15 pack-year history) [40, 41]

- Low socio-economic status [36]

- Low physical activity [41]

The World Health Organisation lists the following criteria to justify a screening programme:

- The condition sought should be an important health problem for the individual and the community. Reduced eGFR (below $75 \mathrm{~mL} / \mathrm{min} / 1.73 \mathrm{~m}^{2}$ ) and proteinuria (ACR $\geqslant 1.1 \mathrm{mg} / \mathrm{mmol}$ ) carry increased risk for the individual patient [42]. Both are independent risk factors for developing endstage renal disease (renal risk) and cardiovascular death. The prevalence of CKD is sufficient to make this important to the community (e.g. in a US cohort: eGFR $<60 \mathrm{~mL} / \mathrm{min} / 1.73 \mathrm{~m}^{2} 8.04 \%$; macroalbuminuria $1.3 \%$; microalbuminuria $8.2 \%$ ) [43].

- There should be an accepted treatment or useful intervention for patients with the disease. Interventions are described in section 2 of this guideline. In brief there is high quality evidence to support interventions to reduce renal and overall risk in patients with diabetes mellitus and CKD. There is also high quality evidence for interventions in non-diabetic proteinuric CKD (urine PCR $>50 \mathrm{mg} / \mathrm{mmol}$ ). Evidence to support reduction of renal risk in non-proteinuric patients without diabetes mellitus, or cardiovascular risk in any non-diabetic CKD patients is based on post hoc analyses of studies which were not specifically designed to address that issue.

- The natural history of the disease should be adequately understood. No evidence is available on the natural history of untreated CKD, and that is unlikely to become available. There is, however, good evidence on the natural history of CKD in various general population cohorts and other subpopulations receiving varying degrees of treatment for cardiovascular risk [4]. Further work is required to clarify which patient subgroups carry the most renal and cardiovascular risk as a consequence of their CKD, and to develop simple tools to help identify them [44].

- There should be a latent or early symptomatic stage. CKD is mostly asymptomatic until eGFR is markedly reduced (typically below $20-30 \mathrm{~mL} / \mathrm{min} /$ $1.73 \mathrm{~m}^{2}$ ) [45], or until there is severe proteinuria. 
In the majority of patients this is preceded by a prolonged asymptomatic stage.

- There should be a suitable and acceptable screening test or examination. $\mathrm{CKD}$ is defined by simple blood (serum creatinine) and urine tests (ACR or PCR, and dipstick urinalysis for haematuria) which cause minimal inconvenience.

- Facilities for diagnosis and treatment should be available. The identification and treatment of $\mathrm{CKD}$ does not require complex facilities. As CKD is part of the QOF in general practice, these facilities should be universally available in the UK.

- There should be an agreed policy on whom to treat as patients. Several guidelines (including this one) provide guidance on which patients should be treated $[3,4]$, and there is reasonable consistency between the guidelines on which patients should be treated.

- Treatment started at an early stage should be of more benefit than treatment started later. As loss of renal function in CKD is generally irreversible, it is assumed that early intervention is of more benefit. The precise stage at which intervention becomes worthwhile is not well-defined except for diabetes mellitus.

- The cost should be economically balanced in relation to possible expenditure on medical care as $\boldsymbol{a}$ whole. There is high quality evidence on the economic case for screening for CKD in patients with diabetes mellitus $[34,46]$. There is limited evidence available for active screening of CKD in non-diabetics. One economic analysis [3] demonstrated that it was cost-effective in patients with hypertension (regardless of age). In patients without diabetes mellitus or hypertension, screening only became cost-effective above age 80 years. This analysis may have over-estimated cost-effectiveness, as it assumed that cases would not be found or treated without screening (which is unlikely to be true, as many patients with hypertension would have their blood pressure treated regardless of the presence or absence of CKD). A recent Canadian analysis suggests that screening is not effective in non-diabetic subjects, but the analysis was based only on the benefits of intervention with angiotensin-converting enzyme inhibitors [34].

- Case finding should be a continuing process and not a once and for all project. This is wellestablished for patients with diabetes mellitus, but not for other populations.
Guideline 1.5 - CKD: Detection and Monitoring of CKD

We recommend that screening for CKD should comprise assessment of the estimated GFR as well as urinalysis. (1A)

\section{Audit measure}

Proportion of patients screened for CKD who have had (a) an assessment of estimated GFR, (b) urinalysis, (c) both an assessment of estimated GFR and urinalysis

\section{Rationale}

CKD is defined by the presence of a persistently reduced GFR, and/or by other evidence of damage to the kidney [15]. The most important evidence of damage other than reduced GFR, is persistent proteinuria, but also includes persistent non-visible haematuria and structural abnormalities detected by imaging or histology.

A recent large meta-analysis demonstrated substantial increased mortality associated with a reduced eGFR below $75 \mathrm{~mL} / \mathrm{min} / 1.73 \mathrm{~m}^{2}$ but also with a urine ACR of $>1.1 \mathrm{mg} / \mathrm{mmol}$ [47]. A US population-based study [48] identified $7.69 \%$ of adults with eGFR $<60 \mathrm{~mL} / \mathrm{min} /$ $1.73 \mathrm{~m}^{2}$. Persistent microalbuminuria was present in $8.2 \%$ and macroalbuminuria in $1.3 \%$. There is overlap between the subjects with reduced eGFR and those with albuminuria, but $5.02 \%$ of the population had albuminuria with an eGFR $\geqslant 60 \mathrm{~mL} / \mathrm{min} / 1.73 \mathrm{~m}^{2}$. A Dutch study of the general population [49] identified reduced renal function in $1.2 \%$, macroalbuminuria in $1.6 \%$ and haematuria in $1.5 \%$. Again there was some overlap between the three groups, but all three tests were required to identify patients with CKD (3.9\%). Both reduced eGFR and macroalbuminuria were associated with an increased risk of subsequent cardiovascular morbidity and mortality. Haematuria was associated with a reduced eGFR compared to the general population, but not with increased risk of cardiovascular morbidity and mortality.

Formal measurements of GFR are not practical in large patient groups. As noted in guideline CKD 1.1 various formulae have been developed to estimate GFR from serum creatinine together with demographic variables. The MDRD formulae are commonly used in the UK.

Dipstick urinalysis has a low positive and negative predictive value for detecting proteinuria (see guideline CKD 1.3), and so some recommend that formal laboratory testing with urine ACR or PCR (according to local

Nephron Clin Pract 2011;118(suppl 1):c71-c100 
practice) is necessary $[3,4]$. Some advocate the use of urinary albumin concentration (rather than adjusted for urine creatinine) on a spot sample [50].

Dipstick urinalysis is required to identify non-visible haematuria, and is preferred to urine microscopy for community-based samples [51]. There is no good evidence of increased cardiovascular or renal risk associated with haematuria, but it may inform investigation of proteinuric patients.

There is no available evidence to support or exclude imaging as a screening tool for CKD. What limited evidence is available examines renal ultrasound in the context of screening for renal cancers.

\section{Guideline 1.6 - CKD: Detection and Monitoring of CKD}

We recommend that detection of an initial abnormal estimated GFR result should prompt a clinical assessment and a repeat test within 2 weeks to assess the rate of change in GFR. If the GFR is stable, a further test should be performed after 90 days to confirm the diagnosis of CKD. If the diagnosis of CKD is confirmed at least 3 assessments of estimated GFR should be made over not less than 90 days to evaluate the rate of change in GFR. (1D)

\section{Audit measure}

1. Proportion of initial abnormal estimated GFR results that are followed by a repeat test within 2 weeks and a further test at 90 days (where appropriate)

2. Proportion of patients with CKD stage 3 or worse in whom the diagnosis has been confirmed by two estimated GFR readings, at least 90 days apart

3. Proportion of patients with a confirmed diagnosis of CKD in whom the rate of change in GFR has been evaluated with at least 3 assessments of GFR over not less than 90 days

\section{Rationale}

Whilst many patients with acute kidney injury (AKI) have obvious symptoms and signs, some do not (e.g. drug-induced interstitial nephritis may be asymptomatic until advanced renal failure has developed). It is difficult to reliably determine whether an asymptomatic patient with reduced GFR has AKI or CKD, in the absence of previous renal function tests. Given the importance of excluding AKI, it is recommended that any patient with a reduced GFR and no previous evidence of renal impairment should have a repeat eGFR within two weeks [3]. The two week limit is not supported by evidence but is based on clinical consensus. The clinical context may mandate more rapid action.

The definition of CKD requires that the reduction of eGFR (or indeed other evidence of kidney damage) be demonstrated to be present for $>90$ days $[3,4]$, and thus requires repeat testing of blood and urine after that time. There is significant biological variation in serum creatinine and to a lesser extent analytical variation. Biological variation is greater in patients with CKD [52] and diabetes mellitus [53] than in the normal population. The intra-individual variation is in part due to diurnal rhythms, and in part due to food intake and hydration status. It should also be appreciated that GFR also varies within individuals in response to fluid status and protein intake. Repeating the serum creatinine in a patient who has not eaten meat for the last 12 hours, will minimise over-diagnosis [54]. It is also important to note if medications which alter serum creatinine have been prescribed or discontinued (most commonly trimethoprim and cimetidine). These drugs compete with creatinine for tubular secretion, and thus raise the serum creatinine (and thus reduce the estimated GFR), but with no effect on actual GFR.

One of the more important issues to establish in a patient with newly diagnosed CKD, is whether the kidney function is stable or deteriorating, and if deteriorating, at what rate. This requires a number of repeat eGFR measurements over a period of time. Based on expert consensus, NICE recommend a minimum of three samples spaced over at least 90 days [3]. The rate of decline of GFR in normal healthy adults is a matter of controversy, but is reported as $0.4-1.2 \mathrm{~mL} / \mathrm{min} /$ year [55]. Rate of GFR decline in renal patients varies substantially between patients, but is typically $\sim 4-5 \mathrm{~mL} /$ min/year [56]. Traditionally kidney function was seen as deteriorating linearly at a predictable rate. This is true in many patients with proteinuric glomerular disease, or with polycystic kidney disease, but does not necessarily apply to the large majority of patients with ill-defined CKD [57, 58]. Some will be stable, or may oscillate or deteriorate unpredictably. Unfortunately, this makes simple linear regression less useful to predict the rate of decline. Viewing the graph of eGFR against time remains a clinically useful approach. If the rate of decline remains unpredictable on the graph, this may prompt more frequent monitoring. Similarly patients with a rapid rate of decline would require more detailed investigation, closer monitoring, consideration of referral to a nephrologist and potentially more active intervention. 


\section{Guideline 1.7 - CKD: Detection and Monitoring of CKD}

We recommend that detection of an initial level of proteinuria equivalent to $<0.5 \mathrm{~g} /$ day of total protein (including levels compatible with microalbuminuria) should be confirmed with a repeat test performed on an early morning urine specimen. For the diagnosis of microalbuminuria 2 abnormal results from 3 specimens are required. (1B)

\section{Audit measures}

1. Proportion of patients with proteinuria equivalent to $<0.5 \mathrm{~g} /$ day in whom the result has been confirmed with a repeat test performed on an early morning urine specimen

2. Proportion of patients with a diagnosis of microalbuminuria in whom the diagnosis has been confirmed with at least 2 abnormal results

\section{Rationale}

Microalbuminuria is a term used to refer to low-level proteinuria which carries increased renal and cardiovascular risk if persistent [47] (in fact the increased risk extends below the microalbuminuria threshold). It is defined as 24 -h urine albumin of $30-300 \mathrm{mg} /$ day, but is usually measured as urine ACR $(3-30 \mathrm{mg} / \mathrm{mmol})$. As men typically have a higher muscle mass and therefore greater urinary creatinine excretion, sex-specific values are usually used for the lower threshold $(2.5 \mathrm{mg} / \mathrm{mmol}$ for men; $3.5 \mathrm{mg} / \mathrm{mmol}$ for women) in the UK. It is not possible to directly convert albuminuria and total proteinuria [28], but $300 \mathrm{mg} /$ day of albuminuria is traditionally taken to equate to $500 \mathrm{mg} /$ day of total proteinuria.

Transient proteinuria at these levels can occur with relatively minor illness, fever or with exercise [59] so it is recommended that proteinuria is defined on repeated samples, to avoid over-diagnosis. Conventionally, two positive out of three is taken to confirm microalbuminuria.

Use of early morning urines to measure ACR gives a more accurate estimate of $24 \mathrm{~h}$ urine albumin, though random samples have acceptable performance (see guideline CKD 1.3). Additionally, early morning urines allow the exclusion of orthostatic proteinuria. In orthostatic proteinuria significant urinary protein is excreted when erect, but when recumbent the urinary protein is completely normal. This usually occurs in young adults, and has no long-term consequences $[60,61]$.

\section{Guideline 1.8 - CKD: Detection and Monitoring of CKD}

We recommend that patients in whom initial urinalysis reveals non-visible/microscopic haematuria should have a urine culture performed to exclude a urinary tract infection. If a UTI is excluded two further tests should be performed to confirm the presence of persistent non-visible/microscopic haematuria. Patients $>40$ years of age with persistent non-visible/microscopic haematuria in the absence of significant proteinuria or a reduced GFR should be referred to a Urology Department for further investigation. (1D)

\section{Audit measures}

1. Proportion of patients with initial detection of non-visible/microscopic haematuria with a urine culture result

2. Proportion of patients with non-visible/microscopic haematuria in whom the result was confirmed with a total of at least 3 tests

3. Proportion of patients with persistent non-visible/ microscopic haematuria in the absence of significant proteinuria or a reduced GFR that were referred to a Urology Department

\section{Rationale}

Non-visible haematuria is common in the general population, with prevalence varying from $0.2-20 \%$ depending on the population definition [62-64]. In most patients it carries no risk, but the primary concern is to exclude structural renal disease, and in particular urological cancers. If non-visible haematuria is persistent, it is essential to exclude cancers, and in the UK this is usually done by fast-track referral to a Urology service. Some have recommended age-specific thresholds (typically $>40$ years) [65], though cancers can occur at younger ages.

Urinary tract infection can cause transient non-visible haematuria, so it is usual to exclude infection before further investigation. Vigorous exercise may also cause transient haematuria, whereas menstruation can cause a spurious positive result. Non-visible haematuria is commonly transient, and so repeated samples are required to establish persistent haematuria warranting further investigation [66].

In association with a reduced eGFR, proteinuria $(>0.5 \mathrm{~g} /$ day) or hypertension, there is an increased likelihood that the patient has glomerular or vasculitic disease, rather than urological disease. Early referral to Nephrology is therefore recommended $[3,4,62]$.

Nephron Clin Pract 2011;118(suppl 1):c71-c100 


\section{Guideline 1.9 - CKD: Detection and Monitoring of CKD}

We recommend that among patients with $\mathrm{CKD}$, the estimated GFR should be monitored regularly. (1B)

\section{Audit measure}

Proportion of patients with CKD with regular monitoring of the estimated GFR at the frequency recommended by NICE or local guidelines

\section{Rationale}

In patients with CKD, GFR is a useful measure of the global function of the kidneys. The prevalence of the complications of renal disease increase as GFR declines, including high blood pressure, hyperphosphataemia, anaemia and metabolic acidosis [67-69]. The optimum frequency of monitoring GFR, however, remains unclear.

In some patients (e.g. primary glomerulopathies, polycystic kidney disease), GFR will decline predictably in a close to linear fashion. However, as noted in guideline CKD 1.6, in many patients with CKD, kidney function may remain stable $[57,58]$. In others it can decline unpredictably. As it is difficult to reliably predict how an individual patient's kidney function will behave, it is difficult to make recommendations on frequency of monitoring of kidney function. SIGN chose to make no recommendation, whilst NICE made recommendations on frequency of GFR monitoring based on consensus:

- Stage 1 and 2 annually

- Stage 3A and B six monthly

- Stage 4 three monthly

- Stage 5 six weekly

We endorse the NICE recommendations, whilst recognising the lack of evidence available to support this approach. Frequency of monitoring must be adjusted in the context of each patient. One would wish to monitor GFR more than annually in a patient with a GFR $>60 \mathrm{~mL} / \mathrm{min} / 1.73 \mathrm{~m}^{2}$, who also had heavy proteinuria given the risk of progressive decline in GFR. Conversely, in a patient with an eGFR of $25 \mathrm{~mL} / \mathrm{min} / 1.73 \mathrm{~m}^{2}$ (i.e. stage $4 \mathrm{CKD}$ ), who was otherwise uncomplicated and had stable function for the preceding year, one could make a case for less frequent monitoring. Given the difference in renal complications between stage $3 \mathrm{~A}$ and $3 \mathrm{~B}$, it would perhaps be more logical to monitor uncomplicated stage $3 \mathrm{~A}$ annually, though this is equally just opinion.

These recommendations are intended for asymptomatic patients. Patients with symptoms, or who are suffering intercurrent illness or undergoing surgery should have their GFR monitored more frequently.

\section{Guideline 1.10 - CKD: Detection and Monitoring of CKD}

We recommend that patients with CKD should have the magnitude of their proteinuria assessed at least annually. (1C)

\section{Audit measure}

Proportion of patients with CKD who have had a measurement of proteinuria within the previous 12 months

\section{Rationale}

A large body of evidence supports the use of proteinuria as an important marker of CKD severity, risk factor for future progression, therapeutic target and marker of therapeutic response (see rationale for guideline CKD 2.3). As such the quantification of proteinuria is essential in the initial investigation of any patient with CKD (guideline CKD 1.3). Proteinuria should also be remeasured to assess response to interventions including antihypertensive medication, ACEI or ARB therapy or where appropriate, immunosuppression. The frequency with which proteinuria is measured will largely be determined by the specific clinical circumstances. There are few data to indicate the optimal frequency for proteinuria monitoring in patients with stable CKD but monitoring at least annually seems clinically reasonable.

\section{Guideline 1.11 - CKD: Detection and Monitoring of CKD}

We recommend that Nephrology Units should negotiate service agreements for the detection and monitoring of CKD, including criteria for referral to a Nephrologist. (1D)

\section{Audit measure}

Proportion of Nephrology Units with specific service agreements for the detection and monitoring of CKD within a defined organisational area

\section{Rationale}

The introduction of eGFR and the K/DOQI Classification was intended to improve detection of previously undiagnosed CKD and resulted in increased numbers of referrals to Nephrology Services in many areas of the UK. Epidemiological studies show that only a minority of patients with CKD are at risk of developing a progressive 
decline in GFR and that the majority do not require further investigation or specialist management delivered by a Nephrology Service [44]. It is also clear that Nephrology Services would not be able to cope if all patients with an eGFR $<60 \mathrm{ml} / \mathrm{min} / 1.73 \mathrm{~m}^{2}$ were to be referred nor could the Health Service afford the associated cost. It is therefore important that each Nephrology Department interact with Commissioners to agree local referral criteria. It is recognised that commissioning arrangements and structures vary within the four countries of the United Kingdom and are in a state of flux. Application of this guideline will therefore depend on local circumstances. Guidance regarding criteria for Nephrology referral has been provided by the National Institute for Health and Clinical Excellence (NICE) [3] and the Scottish Intercollegiate Guideline Network (SIGN) [4]. See also guideline CKD 1.9.

\section{Guideline 1.12 - CKD: Detection and Monitoring of} CKD

We recommend that a Nephrology Unit should establish an easily accessible non-visit-based Specialist advice service for Primary Care Physicians. (1D)

\section{Audit measures}

1. Proportion of all new outpatient attendances that could have been avoided by appropriate nonvisit-based specialist advice
2. Number of requests for non-visit-based advice relative to the total number of referrals per month

\section{Rationale}

A substantial proportion of the population are affected by CKD $(4.4-13.1 \%$ depending on population and definition) $[43,70]$. Only a small proportion of these patients can be directly managed by nephrologists at any one time. To maximise the benefit of secondary care expertise, it needs to be freely available to primary care. Some clinicians in the UK have established telephone help-lines to allow primary care doctors to seek advice on patients with CKD, and CKD in general, thus avoiding unnecessary attendances at secondary care clinics, whilst maintaining quality of care for the patient. Others have achieved a similar goal using email advice lines, perhaps supported with websites [71]. In addition to reducing pressure on secondary care clinics, these approaches have the advantage of reducing patient travel, and ongoing interaction with and education of general practitioners. Studies have yet to be performed to establish whether patients who are currently managed by nephrologists could be equally well managed with this approach. 


\section{References}

1 Manjunath G, Sarnak MJ, Levey AS. Prediction equations to estimate glomerular filtration rate: an update. Current Opin Nephrol Hypertension 2001;10:785-792

-2 Froissart M, Rossert J, Jacquot C et al. Predictive performance of the modification of diet in renal disease and Cockcroft-Gault equations for estimating renal function. J Am Soc Nephrol 2005;16:763-773

3 National Collaborating Centre for Chronic Conditions. Chronic Kidney Disease: National clinical guideline for early identification and management in adults in primary and secondary care. 2008. http://guidance. nice.org.uk/CG73

4 Scottish Intercollegiate Guidelines Network. Diagnosis and management of chronic kidney disease: A national clinical guideline. 2008. http://www.sign.ac.uk/guidelines/fulltext/103/index.html

5 Levey AS, Coresh J, Greene T et al. Using standardized serum creatinine values in the modification of diet in renal disease study equation for estimating glomerular filtration rate. Ann Intern Med 2006;145:247-254

-6 Rule AD, Larson TS, Bergstralh EJ et al. Using serum creatinine to estimate glomerular filtration rate: accuracy in good health and in chronic kidney disease. Ann Int Med 2004;141:929-937

7 Poggio ED, Nef PC, Wang X et al. Performance of the Cockcroft-Gault and modification of diet in renal disease equations in estimating GFR in ill hospitalized patients. Am J Kidney Dis 2005;46:242-252

8 Clase CM, Garg AX, Kiberd BA. Classifying kidney problems: can we avoid framing risks as diseases? BMJ 2004;329:912-915

$\checkmark$ Rainey PM. Automatic reporting of estimated glomerular filtration rate - jumping the gun? Clin Chem 2006;52:2184-2187

10 Levey AS, Stevens LA, Hostetter T. Automatic reporting of estimated glomerular filtration rate - just what the doctor ordered. Clin Chem 2006;52:2188-2193

11 Glassock RJ, Winearls CG. eGFR: Readjusting its rating. Clin J Am Soc Nephrol 2009;4:867-869

12 Stevens LA, Levey AS. Impact of reporting estimated glomerular filtration rate: it's not just about us. Kidney Int 2009;76:245-247

13 Winearls CG, Glassock RJ. Dissecting and refining the staging of chronic kidney disease. Kidney Int 2009;75:1009-1014

14 Levey AS, Stevens LA, Schmid CH et al. A new equation to estimate glomerular filtration rate. Ann Intern Med 2009;150:604-612

15 K/DOQI. K/DOQI clinical practice guidelines for chronic kidney disease: evaluation, classification, and stratification. Am J Kidney Dis 2002;39:S1-S266

16 Levey AS, Eckardt KU, Tsukamoto Y et al. Definition and classification of chronic kidney disease: a position statement from Kidney Disease: Improving Global Outcomes (KDIGO). Kidney Int 2005;67:2089-2100

17 Li PK, Weening JJ, Dirks J et al. A report with consensus statements of the International Society of Nephrology 2004 Consensus Workshop on Prevention of Progression of Renal Disease, Hong Kong, June 29, 2004. Kidney Int Suppl 2005;94:S2-S7

18 Archibald G, Bartlett W, Brown A et al. UK Consensus Conference on Early Chronic Kidney Disease -6 and 7 February 2007. Nephrol Dial Transplant 2007;22:2455-2457

19 Ginsberg JM, Chang BS, Matarese RA, Garella S. Use of single voided urine samples to estimate quantitative proteinuria. New Engl J Med 1983;309:1543-1546

-20 Schwab SJ, Christensen RL, Dougherty K, Klahr S. Quantitation of proteinuria by the use of protein-to-creatinine ratios in single urine samples. Arch Intern Med 1987;147:943-944

21 Rodby RA, Rohde RD, Sharon Z et al. The urine protein to creatinine ratio as a predictor of 24-hour urine protein excretion in type 1 diabetic patients with nephropathy. The Collaborative Study Group. Am J Kidney Dis 1995;26:904-909

22 Morales E, Valero MA, Leon M et al. Beneficial effects of weight loss in overweight patients with chronic proteinuric nephropathies. American Journal of Kidney Diseases 2003;41:319-327

23 Ruggenenti P, Gaspari F, Perna A, Remuzzi G: Cross sectional longitudinal study of spot morning urine protein:creatinine ratio, 24 hour urine protein excretion rate, glomerular filtration rate, and end stage renal failure in chronic renal disease in patients without diabetes. BMJ 1998;316:504-509

24 Lambers Heerspink HJ, Gansevoort RT, Brenner BM et al. Comparison of different measures of urinary protein excretion for prediction of renal events. J Am Soc Nephrol 2010;21:1355-1360

25 Chitalia VC, Kothari J, Wells EJ et al. Cost-benefit analysis and prediction of 24-hour proteinuria from the spot urine protein-creatinine ratio. Clin Nephrol 2001;55:436-447

-26 Shidham G, Hebert LA. Timed urine collections are not needed to measure urine protein excretion in clinical practice. Am J Kidney Dis 2006; $47: 8-14$

27 Jafar TH, Schmid CH, Stark PC et al. The rate of progression of renal disease may not be slower in women compared with men: a patientlevel meta-analysis. Nephrol Dial Transplant 2003;18:2047-2053

28 Methven S, Macgregor MS, Traynor JP et al. Assessing proteinuria in chronic kidney disease: protein-creatinine ratio versus albumincreatinine ratio. Nephrol Dial Transplant 2010:25:2991-2996

29 Hallan SI, Ritz E, Lydersen S et al. Combining GFR and albuminuria to classify CKD improves prediction of ESRD. J Am Soc Nephrol 2009;20:1069-1077

30 van der Velde M, Halbesma N, de Charro FT et al. Screening for albuminuria identifies individuals at increased renal risk. J Am Soc Nephrol 2009;20:852-862

- 31 Matsushita K, van der Velde M, Astor BC et al. Association of estimated glomerular filtration rate and albuminuria with all-cause and cardiovascular mortality in general population cohorts: a collaborative meta-analysis. Lancet 2010;375:2073-2081

32 McIntyre NJ, Taal MW. How to measure proteinuria? Curr Opin Nephrol Hypertens 2008;17:600-603

33 MacGregor MS, Boag DE, Innes A. Chronic kidney disease: evolving strategies for detection and management of impaired renal function. QJM 2006;99:365-375

34 Manns B, Hemmelgarn, B, Tonelli, M et al. Population based screening for chronic kidney disease: cost effectiveness study. BMJ 2010;341:c5869

35 Chadban SJ, Brigganti EM, Kerr PG et al. Prevalence of kidney damage in Australian adults: the AusDiab kidney study. J Am Soc Nephrol 2003;14(Suppl 2):S131-S138

- 36 Coresh J, Astor BC, Greene Tet al. Prevalence of chronic kidney disease and decreased kidney function in the adult US population: third national health and nutrition examination survey. Am J Kidney Dis 2003;41:1-12

37 Drey N, Roderick P, Mullee M et al. A population-based study of the incidence and outcomes of diagnosed chronic kidney disease. Am J Kidney Dis 2003;42:677-684

38 Hallan SI, Dahl K, Oien CM et al. Screening strategies for chronic kidney disease in the general population: follow-up of cross sectional health survey. BMJ 2006;333:1030-1031

- 39 Jurkovitz CT, Qiu Y, Wang C, Gilbertson DT, Brown WW. The Kidney Early Evaluation Program (KEEP): program design and demographic characteristics of the population. Am J Kidney Dis 2008;51(Suppl 2): S3-S12

40 Ejerblad E, Fored CM, Lindblad P et al. Association between smoking and chronic renal failure in a nationwide population-based case-control study. J Am Soc Nephrol 2004;15:2178-2185

41 Stengel B, Tarver CM, Powe NR et al. Lifestyle factors, obesity, and the risk of chronic kidney disease. Epidemiol 2003;14:479-487

42 Chronic Kidney Disease Prognosis Consortium. Association of estimated glomerular filtration rate and albuminuria with all-cause and cardiovascular mortality in genereal population cohorts: a collaborative meta-analysis. Lancet 2010;375:2073-2081

43 Coresh J, Selvin E, Stevens LA et al. Prevalence of chronic kidney disease in the United States. JAMA 2007;298:2038-2047

44 Taal MW, Brenner BM. Renal risk scores: progress and prospects. Kidney Int 2008;73:1216-1219 
-45 Rocco MV, Gassman JJ, Wang SR, Kaplan RM. Cross-sectional study of quality of life and symptoms in chronic renal disease patients: the Modification of Diet in Renal Disease study. Am J Kidney Dis 1997;29:888-896

46 National Institute for Health and Clinical Excellence. Diagnosis and management of type I diabetes mellitus in children, young people and adults. (CG15). London, UK: National Institute for Health and Clinical Excellence, 2004

47 Chronic Kidney Disease Prognosis Consortium. Association of estimated glomerular filtration rate and albuminuria with all-cause and cardiovascular mortality in genereal population cohorts: a collaborative meta-analysis. Lancet 2010;375:2073-2081

48 Coresh J, Selvin E, Stevens LA et al. Prevalence of chronic kidney disease in the United States. JAMA 2007;298:2038-2047

49 Halbesma N, Kuiken D-S, Brantsma AH et al. Macroalbuminuria is a better risk marker than low estimated GFR to identify individuals at risk of accelerated GFR loss in population screening. J Am Soc Nephrol 2006;17:2582-2590

50 Gansevoort RT, Verhave JC, Hillege HL et al. The validity of screening based on spot morning urine samples to detect subjects with microalbuminuria in the general population. Kidney Int 2005; Suppl 94: S28-S35

51 Anderson J, Fawcett D, Feehally J et al. Joint consensus statement on the initial assessment of haematuria. 2008. Available at: www.renal.org/ Libraries/Publications/RA-BAUS_Haematuria_Consensus_Guidelines.sflb.ashx

52 Holzel WG. Intra-individual variation of some analytes in serum of patients with chronic renal failure. Clin Chem 1987;33:670-673

53 Holzel WG. Intra-individual variation of some analytes in serum of patients with insulin-dependent diabetes mellitus. Clin Chem 1987; 33:57-61

54 Preiss DJ, Godber IM, Lamb EJ et al. The influence of a cooked-meat meal on estimated glomerular filtration rate. Ann Clin Biochem 2007; 44:35-42

-55 Douville P, Martel AR, Talbot J, Desmeules S, Langlois S, Agharazii M. Impact of age on glomerular filtration estimates. Nephrol Dial Transplant 2009;24:97-103

56 Klahr S, Levey AS, Beck GJ et al. The effects of dietary protein restriction and blood-pressure control on the progression of chronic renal disease. N Engl J Med 1994;330:877-884
57 John R, Webb M, Young A, Stevens PE. Unreferred chronic kidney disease: a longitudinal study. Am J Kidney Dis 2004;43:825-835

58 Jones C, Roderick P, Harris S, Rogerson M. Decline in kidney function before and after nephrology referral and the effect on survival in moderate to advanced chronic kidney disease. Nephrol Dial Transplant 2006;21:2133-2143

59 Wingo CS, Clapp WL. Proteinuria: potential causes and approach to evaluation. Am J Med Sci 2000;320:188-194

60 Springberg PD, Garrett LE Jr, Thompson AL Jr, Collins NF, Lordon RE, Robinson RR. Fixed and reproducible orthostatic proteinuria: results of a 20-year follow-up study. Ann Intern Med 1982;97:516-519

-61 Rytand DA, Spreiter S. Prognosis in postural (orthostatic) proteinuria: forty to fifty-year follow-up of six patients after diagnosis by Thomas Addison. N Engl J Med 1981;305:618-621

62 Rodgers MA, Hempel S, Aho T, Kelly JD, Kleijnen J, Westwood M. Diagnostic tests used in the investigation of adult haematuria: systematic review and economic evaluation. Health Techno Assess 2006;10:1-276

63 Hiatt RA, Ordonez JD. Dipstick urinalysis screening, asymptomatic microhematuria, and subsequent urological cancers in a populationbased sample. Cancer Epidemiol Biomarkers Prev 1994;3:439-443

64 Mohr DN, Offord KP, Owen RA, Melton LJ 3rd. Asymptomatic microhematuria and urologic disease. JAMA 1986;256:224-229

65 Kelly JD, Fawcett DP, Goldberg LC. Assessment and management of non-visible haematuria in primary care. BMJ 2009;338:a3021

66 Topham PS, Jethwa A, Watkins M, Rees Y, Feehally J. The value of urine screening in a young adult population. Fam Pract 2004;21:18-21

67 Hsu C-y, Chertow GM. Elevations of serum phosphorus and potassium in mild to moderate chronic renal insufficiency. Nephrol Dial Transplant 2002;17:1419-1425

68 Foley RN, Wang C, Ishani A, Collins AJ. NHANES III: influence of race on GFR thresholds and detection of metabolic abnormalities. J Am Soc Nephrol 2007;18:2575-2582

69 Moranne O, Froissart M, Rossert J et al. Timing of onset of CKD-related metabolic complications. J Am Soc Nephrol 2009;20:164-171

70 MacGregor MS. How common is early kidney disease? Nephrol Dial Transplant 2007;22(Suppl 9):ix8-ix18

71 EdRen. Website of the Royal Infirmary of Edinburgh Renal Unit. Available at: renux.dmed.ed.ac.uk/edren (Accessed 1st August, 2010) 
2. Chronic Kidney Disease (CKD) (Guidelines CKD 2.1-2.13)

\section{Guideline 2.1 - CKD: Treatment of patients with CKD}

We recommend that in patients with $\mathrm{CKD}$, systolic blood pressure should be lowered to $<140 \mathrm{mmHg}$ (target range $120-139 \mathrm{mmHg}$ ) and the diastolic blood pressure to $<90 \mathrm{mmHg}$ for the majority. For those with diabetes mellitus or proteinuria of $1 \mathrm{~g} / 24$ hours or greater, the systolic blood pressure should be lowered to $<130 \mathrm{mmHg}$ (target range $120-129 \mathrm{mmHg}$ ) and the diastolic blood pressure to $<80 \mathrm{mmHg}$ unless the risks are considered to outweigh the potential benefits. Antihypertensive therapy should be individualised and lowering the systolic blood pressure to $<120 \mathrm{mmHg}$ should be avoided. (1B)

\section{Audit measures}

1. Proportion of patients with CKD and follow-up for at least 6 months, whose last recorded blood pressure was within the target range specified above unless specifically contraindicated

2. Proportion of patients with CKD and hypertension, followed up for at least 6 months, with a systolic blood pressure $<120 \mathrm{mmHg}$ in the absence of cardiac failure

\section{Rationale}

The treatment of hypertension affords the dual benefit of slowing the rate of progression of CKD and reducing cardiovascular risk in patients with CKD. Whereas the evidence that blood pressure lowering confers renal and cardiovascular protection is clear the optimal level of blood pressure control is less well established. Two large prospective randomised studies have investigated the effect of lower target blood pressures on CKD progression but have failed to provide clear answers $[1,2]$. Nevertheless, the MDRD study did show that the level of proteinuria at baseline significantly modulated the effect of blood pressure lowering such that a lower blood pressure target (MAP $\leqslant 92 \mathrm{mmHg}$, equivalent to $\leqslant 125 / 75 \mathrm{mmHg}$ vs. $\mathrm{MAP} \leqslant 107 \mathrm{mmHg}$, equivalent to $\leqslant 140 / 90 \mathrm{mmHg}$ ) was associated with a slower rate of GFR decline among patients with $>1 \mathrm{~g} /$ day of proteinuria. Furthermore, secondary analysis revealed significant correlations between rate of GFR decline and achieved blood pressure prompting the authors to suggest blood pressure targets of $<130 / 80 \mathrm{mmHg}$ for patients with $<1 \mathrm{~g} /$ day of proteinuria and $<125 / 75 \mathrm{mmHg}$ for those with $>1 \mathrm{~g} /$ day of proteinuria [3]. Long-term follow-up of 840 patients from the MDRD study showed adjusted hazard ratios of $0.68(0.57-0.82)$ and $0.77(0.65-0.91)$ for ESKD and a composite end-point of ESKD and all-cause mortality, respectively for patients originally randomised to the low blood pressure target [4]. In addition, data from the ESCAPE Trial show that among children with CKD receiving treatment with an ACE inhibitor, randomisation to a lower blood pressure target was associated with a significantly reduced risk of reaching ESKD or doubling of serum creatinine [5]. Similarly, a meta-analysis of data from 1860 non-diabetic patients with CKD reported the lowest risk of CKD progression in patients with systolic blood pressure 110 $129 \mathrm{mmHg}$ but a higher risk of progression associated with $\mathrm{SBP}<110 \mathrm{mmHg}$ [6]. A similar note of caution has been sounded by a secondary analysis of data from the Irbesartan Diabetic Nephropathy Trial [7]. Whereas the analysis showed a trend of improved renal and patient survival associated with lower achieved systolic blood pressure, there was a significant increase in all-cause mortality among patients with achieved systolic blood pressure $<120 \mathrm{mmHg}$. Furthermore, secondary analysis of data from the Ongoing Telmisartan Alone and in combination with Ramipril Global EndpoinT (ONTARGET) trial found that subjects who achieved a systolic blood pressure of $<120 \mathrm{mmHg}$ had a significantly higher cardiovascular mortality than those who achieved a systolic blood pressure of $120-129 \mathrm{mmHg}$ [8]. Similarly, the ACCORD study reported no additional benefit with respect to cardiovascular end-points among patients with diabetes randomised to strict blood pressure control aiming to achieve a systolic blood pressure $<120 \mathrm{mmHg}$ (versus conventional control to $<130 / 80 \mathrm{mmHg}$ ), but the lower blood pressure target was associated with more treatment-related adverse events and a greater decline in GFR [9]. There is therefore no evidence to support lowering blood pressure to below a systolic pressure of $120 \mathrm{mmHg}$ and caution should be exercised particularly in patients who may suffer harm from excessive lowering of blood pressure e.g. patients with autonomic neuropathy or postural hypotension.

Many national and international renal, hypertension and diabetes organisations recommend a target blood pressure of $<130 / 80 \mathrm{mmHg}$ for all patients with CKD [10]. Whereas there is some evidence to support a lower target of $<125 / 75 \mathrm{mmHg}$ in patients with $>1 \mathrm{~g} /$ day of proteinuria there is concern that lower blood pressures may be associated with adverse outcomes in some patients. The NICE guidance recommends that 
systolic blood pressure should be controlled to $<140 \mathrm{mmHg}$ (target range $139-120 \mathrm{mmHg}$ ) and the diastolic blood pressure to $<90 \mathrm{mmHg}$. For patients with significant proteinuria (urine ACR $\geqslant 70 \mathrm{mg}$ / $\mathrm{mmol}$; urine PCR $\geqslant 100 \mathrm{mg} / \mathrm{mmol} ; 24$ hour urinary protein excretion $\geqslant 1 \mathrm{~g}$ ) or diabetes and CKD, a lower blood pressure (systolic $<130 \mathrm{mmHg}$, target range 129$120 \mathrm{mmHg}$ and diastolic $<80 \mathrm{mmHg}$ ) is recommended.

The inherent difficulty associated with setting specific numeric targets for blood pressure control as well as the limited nature of the supporting evidence has recently been discussed in detail [11]. In view of the Gaussian distribution of blood pressure values in a population, setting a specific minimum target for blood pressure will result in achieved mean blood pressures substantially below this value. Given recent data discussed above regarding the potential dangers of excessive blood pressure lowering, it must be emphasised that antihypertensive therapy should be individualised and that lowering systolic blood pressure to below $120 \mathrm{mmHg}$ should be avoided.

\section{Guideline 2.2-CKD: Treatment of patients with CKD}

We recommend that Angiotensin-Converting Enzyme Inhibitor (ACEI) or Angiotensin Receptor Blocker (ARB) treatment should form part of the antihypertensive therapy of patients with $\mathrm{CKD}$ and urinary protein excretion of $>0.5 \mathrm{~g} /$ day unless there is a specific contraindication. (1A)

\section{Audit measure}

Proportion of proteinuric CKD patients (as defined above) without contraindications, who have an ACEI or ARB on their last recorded list of chronic medications

\section{Rationale}

Several large prospective randomised controlled trials among different groups of patients with CKD provide evidence that ACEI or ARB treatment affords significant renal protection in addition to that attributable to blood pressure lowering. Specifically, ACEI treatment has been shown to slow CKD progression among patients with type 1 diabetes mellitus and established nephropathy [12] as well as patients with non-diabetic CKD and proteinuria $>1 \mathrm{~g} /$ day [13-15]. Furthermore a recent randomised study has shown that ACEI treatment may afford significant renal protection $(43 \%$ reduction in risk of doubling serum creatinine, ESKD or death) in non-diabetic patients with advanced renal disease (serum creatinine $264-440 \mu \mathrm{mol} / \mathrm{l}$ ) [16]. A meta-analysis of data from 11 randomised controlled trails that compared ACEI with other antihypertensives among patients with predominantly non-diabetic CKD showed a significantly lower risk of ESKD incidence (relative risk 0.69; 95\%CI 0.51-0.94) associated with ACEI treatment after adjustment for differences in level of blood pressure control [17]. The analysis also found greater renal protective benefit associated with ACEI treatment in patients with higher levels of baseline proteinuria but no benefit could be shown for those with proteinuria $<0.5 \mathrm{~g} /$ day. This analysis did not however include data from the AASK study, which reported a lower incidence of the combined end-point of $>50 \%$ GFR reduction, ESKD or death among African American patients with mild baseline proteinuria (mean $0.6 \mathrm{~g} /$ day among males and $0.4 \mathrm{~g} /$ day among females) randomised to ACEI treatment versus a calcium channel blocker or a $\beta$-blocker [15]. ARB treatment has been shown to afford significant renal protection in two large randomised studies of patients with type 2 diabetes and established nephropathy $[18,19]$. A meta-analysis of clinical trials among patients with diabetic nephropathy confirmed that ACEI or ARB treatment was associated with improved renal outcomes versus placebo. ACEI treatment was also associated with lower mortality but ARB treatment was not [20]. Few trials have directly compared ACEI with ARB treatment but one study has found no significant difference among patients with diabetic nephropathy [21] and another reported no difference in renal outcomes or mortality among hypertensive patients with cardiovascular risk factors, some of whom had CKD [22].

Two large prospective randomised controlled studies have reported significant reductions in cardiovascular morbidity and mortality associated with ACEI treatment among patients with a high risk for future cardiovascular events $[23,24]$. On the other hand the primary analysis of Prevention of Events with ACE inhibition (PEACE) trial found no such benefit among patients with stable coronary heart disease and low risk of cardiovascular events [25]. Interestingly a secondary analysis of the PEACE trial data found a higher risk of death among patients with an estimated GFR of $<60 \mathrm{ml} / \mathrm{min} / 1.73 \mathrm{~m}^{2}$ at baseline and a significant reduction in all cause mortality associated with ACEI treatment in this subgroup [26]. Whereas none of the above studies specifically included patients with CKD and all excluded patients with moderate or severe renal impairment, these data do provide support for the notion that ACEI treatment 
reduces cardiovascular risk in high-risk patients. As cardiovascular disease remains the most important cause of death among CKD patients it seems reasonable to recommend ACEI or ARB treatment for reduction of cardiovascular risk as well as slowing of CKD progression.

Insufficient evidence exists to recommend the use of combination ACEI and ARB therapy. The formal withdrawal of the only randomised trial to report benefit with respect to hard renal outcomes in patients with CKD and proteinuria (due to serious concerns regarding the conduct of the study and analysis of the data) [27] has reduced the evidence base to several relatively small studies that showed greater reduction of proteinuria (a surrogate end-point) with combination therapy [28]. Moreover a large trial of combination therapy in patients with hypertension and increased cardiovascular risk but mild or absent proteinuria reported no additional benefit with respect to cardiovascular outcomes but did observe an increase in the combined end-point of creatinine doubling, ESKD or death [22], indicating that combination ACEI and ARB therapy may be associated with adverse outcomes in some patient groups.

\section{Guideline 2.3 - CKD: Treatment of patients with CKD}

We suggest that patients with $\mathrm{CKD}$ and proteinuria $>0.5 \mathrm{~g} /$ day should have their ACEI or ARB and other antihypertensive treatment escalated to achieve the lowest possible level of proteinuria. (2C)

\section{Audit measure}

Proportion of patients with CKD and proteinuria who achieve a decrease in proteinuria to $<0.5 \mathrm{~g}$ /day

\section{Rationale}

Patients with significant proteinuria are at increased risk of renal and cardiovascular events [29]. Treatment of blood pressure to a lower than usual target of $<130$ / $80 \mathrm{mmHg}$ has been demonstrated to reduce the risk of renal events in non-diabetic patients with proteinuria $>1 \mathrm{~g} /$ day [30]. Similarly treatment with ACEi/ARB has been shown to reduce risk of renal events in non-diabetic patients with proteinuria $>0.5 \mathrm{~g} /$ day [17].

The degree of renal risk is associated with the baseline and follow-up level of proteinuria [31, 32]. Post hoc analyses demonstrate that greater reductions in proteinuria are associated with greater reductions in renal risk [31-34]. For example, in the African-American Study of Kidney Disease, a more than 50\% reduction in baseline proteinuria by six months was associated with approximately $75 \%$ reduction in the risk of end-stage kidney disease [32]. In the Irbesartan Diabetic Nephropathy Trial each halving of albuminuria gave a 56\% reduction in the risk of renal failure [33]. Furthermore, in one prospective study, proteinuric ( $>1 \mathrm{~g} /$ day) patients with $\mathrm{CKD}$ randomised to the maximum anti-proteinuric dose of ACEI or ARB treatment evidenced a significantly lower incidence of the primary end-point of ESRD or creatinine doubling than those randomised to fixed dose ACEI or ARB treatment despite equivalent blood pressure control [35].

Thus, if the systolic blood pressure target of $<130 \mathrm{mmHg}$ has been achieved, it is reasonable to continue escalating the antihypertensive medication to achieve further reductions in proteinuria to less than $0.5 \mathrm{~g} /$ day. However, systolic blood pressure below $120 \mathrm{mmHg}$ may increase the risk of loss of renal function [31], so caution is warranted (see Guideline CKD 2.1).

\section{Guideline 2.4-CKD: Treatment of patients with CKD}

We recommend that patients with diabetes mellitus and microalbuminuria should be treated with an ACEI or ARB, titrated to maximum licensed antihypertensive dose if tolerated, regardless of the initial blood pressure, unless these drugs are specifically contraindicated. Hypotension should be avoided. (1A)

\section{Audit measures}

1. Proportion of patients with diabetes mellitus and microalbuminuria (without specific contraindications) who had an ACEI or ARB on their last recorded list of chronic medications

2. Proportion of patients receiving an ACEI or ARB for diabetes and microalbuminuria who received the maximum licensed antihypertensive dose (or maximum dose tolerated without hypotension) on their most recent prescription

\section{Rationale}

The presence of microalbuminuria in patients with diabetes mellitus represents the earliest stage of diabetic nephropathy and identifies patients at increased risk of developing overt diabetic nephropathy characterised by a progressive decline in renal function. There is a large body of evidence indicating that in diabetic patients with microalbuminuria, ACEI or ARB treatment reduces or delays progression from microalbuminuria to overt nephropathy and reduces cardiovascular risk [36]. 
Among type 1 diabetic patients a meta-analysis of 12 studies including 689 patients reported that ACEI treatment was associated with a marked reduction in the risk of progression to overt nephropathy (odds ratio 0.38, $95 \%$ CI 0.25 to 0.57 ) [37]. Among patients with type 2 diabetes the evidence is somewhat less clear. On the one hand several studies have shown a reduction in the amount of microalbuminuria or a decrease in the risk of progression from microalbuminuria to overt nephropathy (risk reduction 24-67\%) with ACEI treatment [38-42] but one relatively large study found no renal protective benefit of ACEI over $\beta$-blocker treatment among hypertensive type 2 diabetic patients with normo- or microalbuminuria [43]. It should also be noted, however, that subgroup analysis of the HOPE Study found that ACEI treatment was associated with a $25 \%$ reduction in the combined primary end-point of myocardial infarction, stroke or cardiovascular death as well as a $24 \%$ reduction in the incidence of overt nephropathy among type 2 diabetic patients with normo- or microalbuminuria [42]. One large trial has shown a renal protective benefit of ARB treatment among type 2 diabetic patients with microalbuminuria. Importantly Irbesartan treatment (at $150 \mathrm{mg}$ or $300 \mathrm{mg} /$ day) was associated with a dose-dependent reduction in the incidence of overt proteinuria (hazard ratio $0.30 ; 95 \% \mathrm{CI}$ 0.14 to 0.61 for $300 \mathrm{mg}$ dose) [44]. A meta-analysis of studies that included patients with diabetic nephropathy reported that treatment with an ACEI or ARB was associated with reduced progression from micro- to macroalbuminuria and increased regression from micro-to normoalbuminuria [45].

Based on the results of the above study that investigated the effects of Irbesartan [44] we recommend that the dose of ACEI or ARB should be increased to the maximum licensed antihypertensive dose (British National Formulary) or the maximum tolerated dose. Some published evidence suggests that doses of ARB higher than the currently licensed maximum may afford additional benefit [46]. At present, however, the evidence is not strong enough to recommend higher doses of ARB as standard treatment for microalbuminuria.

Whether or not patients with diabetes and hypertension but without microalbuminuria should be treated with ACEI or ARB to prevent microalbuminuria remains uncertain. Several trials in patients with type 1 diabetes have found no benefit with either ACEI or ARB treatment $[47,48]$. Indeed in one study ARB treatment was associated with an increased incidence of microalbuminuria [49]. On the other hand, two large trials in patients with type 2 diabetes have reported significant reductions in the incidence of microalbuminuria with ACEI [50] or ARB [51] treatment whereas one relative small trial found no benefit with ACEI treatment [52]. In the BENEDICT Trial, treatment with trandolapril alone or in combination with verapamil, significantly delayed the onset of microalbuminuria. GFR was not affected by the treatment and there was no difference in adverse events between groups [50]. In the ROADMAP trial treatment with olmesartan significantly reduced the cumulative incidence of microalbuminuria. There was, however, a small but significant reduction in GFR associated with olmesartan treatment. Although total mortality was similar between the groups there was a significantly higher cardiovascular mortality observed in the olmesartan group. The absolute number of cardiovascular deaths was, however, very low $(0.7 \%$ versus $0.1 \%$ ) and the authors propose that the increased cardiovascular mortality was due to hypotensive episodes in subjects with pre-existing cardiovascular disease (CVD) [51]. Whether or not the prevention of microalbuminuria by these interventions translates into long-term benefit with respect to renal or cardiovascular outcomes remains to be determined. Nevertheless, it seems reasonable to recommend the use of ACEI or ARB treatment as part of the antihypertensive therapy for patients with type 2 diabetes but hypotension should be avoided, particularly in those with cardiovascular disease.

\section{Guideline 2.5 - CKD: Treatment of patients with CKD}

We recommend that patients with diabetes mellitus and CKD should achieve good glycaemic control. (1B)

\section{Audit measure}

1. Proportion of patients with diabetic nephropathy and follow-up for at least 6 months, whose last recorded $\mathrm{HBA}_{1 \mathrm{C}}$ was below their agreed target

2. Average $\mathrm{HBA}_{1 \mathrm{C}}$ of all patients with diabetes mellitus and CKD

\section{Rationale}

The DCCT [53] and UKPDS [54] trials provided strong evidence that improved glycaemic control prevents the development of microalbuminuria as well as other microvascular complications in patients with type 1 and 2 diabetes mellitus, respectively. Moreover, long term follow up of participants in the UKPDS trial 
reported that the reduction in risk of microvascular complications observed in those randomised to tight glycaemic control persisted during 10 years of post trial follow up, despite the loss of between group differences in glycosylated haemoglobin after the first post trial year [55]. Subjects previously in the intensive glycaemic control group also evidenced a lower incidence of myocardial infarction and death from any cause. In contrast, evidence of the potential renal protective benefits of good glycaemic control in patients who already have microalbuminuria is not conclusive. Among patients with type 1 diabetes, only $2[56,57]$ of 5 small studies [56$60]$ found a reduction in progression to overt nephropathy in patients randomised to improved versus normal glycaemic control. Nevertheless, the reported histological reversal of diabetic glomerular lesions in type 1 diabetic patients with normo- or microalbuminuria after pancreatic transplantation does suggest that improved glycaemic control is of benefit in the long term [61]. In the UKPDS Study improved glycaemic control was associated with a delay in the development of overt proteinuria and slowing of the rate of increase in serum creatinine among type 2 diabetic patients with microalbuminuria [54]. Unfortunately there are no data available regarding the effect of glycaemic control on the progression of established diabetic nephropathy. Nevertheless patients with all stages of diabetic nephropathy remain at increased risk of other microvascular complications and good glycaemic control should therefore be maintained to reduce this risk. The precise level of glycaemic control to be achieved remains somewhat controversial. In the DCCT and UKPDS trials the mean achieved $\mathrm{HBA}_{1 \mathrm{C}}$ was $7-7.5 \%$ (53-59 mmol/ mol) $[53,54]$. The Joint British Societies' 'Guidelines on prevention of cardiovascular disease in clinical practice' recommends an 'optimal target' for $\mathrm{HBA}_{1 \mathrm{C}}$ of $<6.5 \%(<48 \mathrm{mmol} / \mathrm{mol})$ but an 'audit standard' of $<7.5 \%(<59 \mathrm{mmol} / \mathrm{mol})$ [62]. Two recent randomised trials have indicated that aiming for more intensive glycaemic control may be associated with adverse events among patients with type 2 diabetes. One trial reported an increased mortality and no reduction in major cardiovascular events associated with randomisation to $\mathrm{HBA}_{1 \mathrm{C}}$ $<6 \% \quad(<42 \mathrm{mmol} / \mathrm{mol})$ [63] whereas another trial reported reduced microvascular complications (due largely to a $21 \%$ relative reduction in the incidence of diabetic nephropathy) but no benefit with respect to macrovascular events or survival and a small but significantly increased risk of severe hypoglycaemia among those randomised to $\mathrm{HBA}_{1 \mathrm{C}}<6.5 \%(<48 \mathrm{mmol} / \mathrm{mol})$
[64]. Due to concerns about the increased risk of hypoglycaemia in patients with reduced renal function, we recommend a general target of $\mathrm{HBA}_{1 \mathrm{C}}<7.5 \%$ $(<59 \mathrm{mmol} / \mathrm{mol})$ for patients with CKD but have avoided placing a specific target in the audit measures. For a population to achieve similar glycaemic control to the DCCT and UKPDS populations, approximately $50 \%$ should achieve this target. Whereas the benefits of good glycaemic control are well established, the potential risks should also be considered and therapeutic targets should therefore be individualised and agreed with the patient.

\section{Guideline 2.6 - CKD: Treatment of patients with CKD}

We recommend that patients with CKD should have an annual formal assessment of their cardiovascular risk factors including lipid profile, BMI, exercise, alcohol and smoking habits as well as a review of interventions to reduce cardiovascular risk. (1D)

\section{Audit measure}

Proportion of CKD patients with a formal assessment of cardiovascular risk factors documented in their records during the past year

\section{Rationale}

It is increasingly recognised that CKD is associated with a high risk of cardiovascular morbidity and that cardiovascular disease is the most common cause of death among CKD patients. Moreover in some populationbased studies of patients with CKD, the risk of cardiovascular death has been reported to exceed substantially the risk of progression to ESKD [65]. Unfortunately most cardiovascular risk estimation equations developed for the general population do not take account of kidney function or albuminuria. Studies have shown that such equations substantially underestimate cardiovascular risk in CKD patients [66]. One recent equation, QRISK 2 [67], does include a term for CKD, but treats this as a categorical variable and does not consider the degree to which GFR is reduced or the magnitude of albuminuria, both of which are important predictors of cardiovascular risk [68]. It is hoped that future cardiovascular risk estimation tools will include more detailed information regarding GFR and albuminuria. Until such equations have been developed it is important to identify patients with CKD as being at increased cardiovascular risk and to consider interventions to correct as many cardiovascular risk factors as possible. 
Whereas specific interventions for improving cardiovascular risk have not been widely studied in patients with $\mathrm{CKD}$, it seems reasonable to ensure that $\mathrm{CKD}$ patients are afforded the benefit of treatments shown to reduce cardiovascular risk in other patient populations. One study has examined the effect of a combined approach of intensive intervention to reduce cardiovascular risk in patients with type 2 diabetes mellitus and microalbuminuria [69]. Interventions included lower blood pressure targets, ACEI, aspirin and lipidlowering treatment, tight glycaemic control, low fat diet, smoking cessation and exercise. In patients randomised to the intensive intervention arm of the study there was a significant reduction in cardiovascular events (HR 0.47 ; 95\%CI $0.24-0.73$ ) over a mean of 7.8 years [69]. Further follow up after completion of the trial found significantly improved survival among patients previously randomised to the intensive intervention group after a mean of 13 years [70]. Two large clinical trials have found that the routine use of statins for primary prevention in haemodialysis patients was not associated with a reduction in cardiovascular events [71, 72]. Nevertheless, this should not be interpreted to mean that statins are of no benefit among haemodialysis patients with significant dyslipidaemia or for secondary prevention. Furthermore, studies in the general population that have included subjects with mild to moderately reduced GFR have found that such patients benefit from statin therapy at least as much as those with normal GFR [73]. Similarly, a meta-analysis of 26 studies comparing statin therapy with placebo in CKD patients not requiring dialysis found a significant reduction in all cause and cardiovascular mortality associated with statin therapy [74].

\section{Guideline 2.7 - CKD: Treatment of patients with CKD}

We recommend that patients with CKD and dyslipidaemia should be treated in accordance with current guidance for the general population. (1C)

\section{Audit measures}

1. Proportion of CKD patients with indications for lipid lowering therapy as defined by NICE/JBS 2

2. Proportion of CKD patients with indications for lipid lowering therapy as defined by NICE/JBS 2, who are receiving lipid lowering therapy

3. Proportion of CKD patients who currently do not have an indication for lipid lowering therapy as defined by NICE/JBS 2 but who are receiving a lipid lowering agent

Guideline on Detection, Monitoring and Management of Patients with CKD

\section{Rationale}

Chronic kidney disease is associated with an increased incidence of cardiovascular disease. Both reduced eGFR and proteinuria are independent risk factors for mortality $[29,75,76]$. Statins are a well-established treatment to reduce cardiovascular risk in a wide range of populations for both primary and secondary prevention [77]. The benefits are effective regardless of baseline cholesterol levels, with an approximate $20 \%$ reduction in the 5-year risk of cardiovascular events per $1 \mathrm{mmol} / \mathrm{L}$ reduction in serum cholesterol. Both NICE and the Joint British Societies have produced guidance on assessing risk and managing lipids in the general population $[78,79]$.

However, there are no large trials of lipid-lowering therapy which specifically enrolled patients with stages 3-4 CKD. Post hoc analysis and meta-analysis of studies which included some patients with CKD demonstrated that statins remained effective at reducing cardiovascular risk and mortality [80-82]. The patients in this group had relatively mild CKD (typically stage $3 \mathrm{~A}$ ), and most were included in these trials because of other cardiovascular risk factors and not because of CKD per se. A meta-analysis showed a 19\% reduction in cardiovascular mortality, with a $1.1 \mathrm{mmol} / \mathrm{L}$ reduction in low density lipoprotein cholesterol in patients with CKD [80].

However, two large trials in haemodialysis patients $[72,83]$ showed no evidence of benefit from statins (atorvastatin and rosuvastatin) on cardiovascular mortality or events. A trial of fluvastatin in renal transplant patients reduced cardiovascular events, but also showed no significant effect on the pre-specified primary endpoint [84]. These results were surprising, but may reflect the difficulty of demonstrating benefit in patients with advanced renal disease and multiple competing risks for death. However, the dyslipidaemia of renal disease is different from the general population [85], and alternate mechanisms for cardiovascular death such as vascular calcification and arrhythmia related to left ventricular hypertrophy also exist, and are unlikely to be amenable to lipid lowering therapy.

Currently, it seems sensible to treat lipid-lowering therapy in stage $3 \mathrm{CKD}$ in the same way as the general population $[78,79]$. Caution may be appropriate in more advanced CKD, until further evidence is available. Preliminary results of a large randomised-controlled trial of simvastatin and ezetemibe treatment for primary prevention in stages 3-5 CKD [86] reported a 17\% reduction in the relative risk of major atherosclerotic events in the treatment group but the final results have 
not yet been published and could therefore not be included in this guideline.

To justify primary prevention with lipid-lowering therapy, an estimate of cardiovascular risk is required. Available tools $[87,88]$ to assess cardiovascular risk do not adequately incorporate the impact of reduced eGFR or increased proteinuria. Until such revised tools are available, and given the lack of specific evidence for intervention in the CKD population, the standard tools are still recommended for use despite the expected higher risk.

Guideline 2.8-CKD: Treatment of patients with CKD

We suggest that smoking status and action taken should be documented in the patient record at each nephrology clinic visit. (1D)

\section{Audit measures}

1. Proportion of CKD patients with smoking status recorded in their last record entry

2. Proportion of CKD patients who are current smokers that received an offer of assistance with smoking cessation during the past year of follow-up

3. Proportion of smoking CKD patients who ceased smoking during the past year

\section{Rationale}

Smoking has been identified as a risk factor for the development of progressive renal disease in the general population [89-93] as well as in patients with essential hypertension [94] and diabetes mellitus [95-98]. Other studies have found that smoking is associated with an increased risk of CKD progression among patients with primary glomerular nephropathies [99], IgA nephropathy or adult polycystic kidney disease [100], lupus nephritis [101] and CKD stage 1-2 [102]. Unfortunately few studies have examined the impact of smoking cessation on renal disease. In one relatively small study 16 patients who stopped smoking evidenced a slower rate of decline in renal function and a lower incidence of ESKD than 26 patients who refused to stop [103]. Whereas the evidence of benefit regarding smoking cessation and renal protection is limited, the clear evidence of smoking as a risk factor for cardiovascular and respiratory disease makes smoking cessation a critical intervention for improving survival in CKD patients.

Guideline 2.9-CKD: Treatment of patients with CKD

We suggest that patients with CKD and a BMI of $>30 \mathrm{~kg} / \mathrm{m}^{2}$ should receive dietary advice to assist them in losing weight. (2D)

\section{Audit measure}

Proportion of patients with CKD and obesity who have received dietary advice to assist weight loss

\section{Rationale}

In the general population, obesity is associated with increased rates of hypertension, vascular disease, type 2 diabetes mellitus and heart failure [104]. Although associated with conditions that predispose to CKD, there is only limited evidence that obesity is an independent risk factor for CKD [105-107]. There is no convincing evidence to support an impact of obesity on the rate of progression of CKD [108].

To balance against the risks of obesity is the paradoxical observation that obese patients have a better survival once established on dialysis. This has been observed in both the USA and Europe [109, 110].

There is no high quality evidence on the impact of reducing obesity on CKD incidence and progression. Several small studies have examined the impact of bariatric surgery, showing improvement in blood pressure control, eGFR, proteinuria, markers of inflammation and adipokine profile after weight loss [111114]. These findings should be interpreted with caution given the unknown validity of the eGFR formulae in the morbidly obese, and the uncertain impact of dramatic weight loss on lean body mass. Future studies will require the use of formal measurements of GFR and hard renal endpoints such as incidence of ESRD and creatinine doubling.

Given the impact of obesity on general health and cardiovascular health in particular, it is thought to be sensible to recommend weight reduction using diet in patients with CKD.

\section{Guideline 2.10 - CKD: Treatment of patients with CKD}

We recommend that patients with CKD should receive dietary advice to restrict their sodium intake to $<2.4 \mathrm{~g} /$ day (100 $\mathrm{mmol} /$ day or $<6 \mathrm{~g} /$ day of salt). (1B)

\section{Audit measure}

Proportion of patients with CKD who have received dietary advice to assist dietary sodium restriction

\section{Rationale}

Western populations consume substantially higher amounts of sodium than is necessary, and this is associated with a higher prevalence of hypertension and cardiovascular disease $[115,116]$. In the UK, average 
dietary salt ${ }^{*}$ intake is $9.4-10.6 \mathrm{~g} /$ day in men and 6.8 $7.7 \mathrm{~g} /$ day in women [117]. The DASH-sodium study $[118,119]$ was a randomised controlled trial of dietary sodium restriction performed in subjects without renal impairment. Reducing salt intake from $8.2 \mathrm{~g} /$ day to $6.2 \mathrm{~g} /$ day gave a reduction of $2.1 \mathrm{mmHg}$ in systolic blood pressure. Reducing further to $3.7 \mathrm{~g} /$ day gave a further $4.6 \mathrm{mmHg}$ reduction. These effects were more marked in hypertensive subjects and in older subjects.

There is relatively little evidence on whether a high sodium intake is specifically associated with poorer renal outcomes, or whether reducing sodium intake improves renal outcomes [120]. However, given the impact of sodium reduction on blood pressure, and the known impact of high blood pressure on renal function and proteinuria, it seems sensible to adopt the general population recommendation of maintaining dietary sodium at $<6 \mathrm{~g} /$ day.

Clinicians should be aware that salt substitutes contain significant amounts of potassium and should be avoided in patients with CKD. Furthermore they still contain substantial amounts of sodium (e.g. LoSalt ${ }^{\circledR}$ contains $13 \mathrm{~g}$ of sodium per $100 \mathrm{~g}$ [121], equivalent to $33 \mathrm{~g}$ of salt).

${ }^{\star}$ Intake is quoted as dietary salt in g/day. To convert to dietary sodium in $\mathrm{g} /$ day multiply by 0.394 . To convert to $\mathrm{mmol} /$ day of salt or sodium multiply by 17.1 .

\section{Guideline 2.11 - CKD: Treatment of patients with CKD}

We recommend that patients with CKD who develop hyperkalaemia or hyperphosphataemia should receive dietary advice to assist dietary restriction of potassium and phosphate. (1C)

\section{Audit measures}

1. Proportion of patients with CKD stages 4 and 5 who have received dietary advice to assist dietary restriction of potassium and phosphate

2. Proportion of patients with CKD stages $1-3$ and hyperkalaemia or hyperphosphataemia who have received dietary advice to assist dietary restriction of potassium and phosphate

\section{Rationale}

Hyperkalaemia is a common complication in patients with CKD as their GFR declines [122, 123]. Although it can occur at any GFR, it becomes increasingly common as GFR declines below $40-60 \mathrm{~mL} / \mathrm{min} / 1.73 \mathrm{~m}^{2}$.
Additionally, medications commonly used in CKD (ACEi, ARB, beta-blockers, aldosterone antagonists) increase the risk of hyperkalaemia further [124]. Hyperkalaemia can cause arrhythmias and death. Whilst this can be preceded by other symptoms such as muscle weakness, it may present as cardiac arrest [125]. In patients with $\mathrm{CKD}$, dietary advice can substantially ameliorate hyperkalaemia, potentially allowing ongoing optimal treatment of hypertension and proteinuria. Dietary advice, and adjustment of medications is usually sufficient to control hyperkalaemia in stages 1-4 CKD.

Hyperphosphataemia increases in prevalence as GFR declines becoming increasingly common as GFR declines below $40 \mathrm{~mL} / \mathrm{min} / 1.73 \mathrm{~m}^{2}[122,123]$. It is associated with increased risk of death [126], thought to be mediated via vascular calcification. Phosphate content of food is closely related to its protein content, but food additives [127], and soft drinks [128] are also major contributors to dietary phosphate, and are not readily identified from food labelling.

Elevated serum phosphate levels can be reduced with advice on dietary restriction [129], with effects on other mineral metabolism markers which are thought to be beneficial. Caution is needed with dietary advice to avoid unnecessary restriction of protein [130]. Given that, and the often masked content of phosphate in processed foods, this advice needs to be delivered by a skilled individual - usually a renal dietician.

As GFR declines further, dietary restriction alone will usually become insufficient to control serum phosphate, necessitating the use of phosphate binders [131].

\section{Guideline 2.12 - CKD: Treatment of patients with CKD}

We suggest that patients with CKD should receive advice to perform regular moderate exercise. (2D)

Audit measures

1. Proportion of patients with CKD who have received advice to undertake regular exercise

2. Proportion of patients with CKD who report performing regular moderate exercise

\section{Rationale}

It is well-established in the general population that regular, moderate exercise reduces the risk of cardiovascular disease [132, 133]. Although there are no specific studies examining the benefits of exercise interventions on cardiovascular outcomes in patients with $\mathrm{CKD}$, given the increased cardiovascular risk in the 
CKD population it would seem sensible to recommend regular, moderate exercise. Regular exercise may also contribute to weight loss (see guideline CKD 2.9). Small, relatively short-term studies give no clear evidence of renal-specific benefits of exercise [3] and further studies are required to investigate this further.

\section{Guideline 2.13 - CKD: Treatment of patients with CKD}

We recommend that patients with CKD should be referred for assessment by a Nephrology Department according to the NICE Guidelines. (1B)

\section{Audit measures}

1. Proportion of patients on Primary Care CKD registers who have been referred to a Nephrology Department

2. Proportion of patients on Primary Care CKD registers with an indication for referral to a Nephrology Department

3. Proportion of patients on Primary Care CKD registers with an indication for referral, who have been referred to a Nephrology Department

\section{Rationale}

There is little or no evidence available on the optimum setting for management of patients with CKD. Given the high prevalence of CKD [134], and the relatively low number of nephrologists in the UK, it is evident that most patients will be managed in primary care. The large majority of patients with CKD stage 3 will not progress to end-stage kidney disease $[135,136]$, and will not require complex investigations or interventions, so primary care is likely to offer at least an equivalent level of care.

However, there is substantial evidence to show that patients who require renal replacement therapy (i.e. dialysis and/or kidney transplantation) have increased morbidity, reduced survival and increased cost if they present to a nephrologist late in their illness [137, 138]. It is essential that patients who will require RRT are referred in a timely manner.

The challenge is to identify the minority of patients who will benefit from secondary care assessment and management. Patients at risk of progressive decline in their GFR have the greatest potential for benefit from interventions to slow down that progression. Various parameters have been shown to predict progressive decline, with reduced eGFR, increased proteinuria and poorly controlled blood pressure consistently being identified [139].

Some patients with CKD will require more complex management than is usually provided in primary care (e.g. patients requiring immunosuppressive therapy, treatment of renal anaemia, treatment of CKD mineral and bone disorder or metabolic acidosis). These conditions would usually be beyond the scope of primary care, and should be referred to a nephrologist.

The SIGN guideline [4] recognised that systems of care may differ, and will affect whether or not patients should be referred to a nephrologist. The NICE guideline [3] also recognised the lack of evidence, but on the basis of consensus suggested that nephrologists were needed when the patient requires diagnosis or treatment for kidney disease, is at risk of progressive renal disease or needs planning for renal replacement therapy. NICE recommends that the following patients should normally be referred to a consultant nephrologist:

- Stage 4 or 5 CKD

- Heavy proteinuria (urine ACR $\geqslant 70 \mathrm{mg} / \mathrm{mmol}$; urine PCR $\geqslant 100 \mathrm{mg} / \mathrm{mmol} ; 24 \mathrm{~h}$ urine protein $\geqslant 1 \mathrm{~g} /$ day) unless due to diabetes and already appropriately treated

- Proteinuria (urine ACR $\geqslant 30 \mathrm{mg} / \mathrm{mmol}$; urine PCR $\geqslant 50 \mathrm{mg} / \mathrm{mmol} ; 24 \mathrm{~h}$ urine protein $\geqslant 0.5 \mathrm{~g} /$ day) if accompanied by haematuria

- Rapidly declining GFR ( $>5 \mathrm{~mL} / \mathrm{min} / 1.73 \mathrm{~m}^{2}$ in one year, or $>10 \mathrm{~mL} / \mathrm{min} / 1.73 \mathrm{~m}^{2}$ within 5 years)

- Hypertension that remains poorly controlled despite the use of at least 4 antihypertensive drugs at therapeutic doses

- People with, or suspected of having rare or genetic causes of CKD

- Suspected renal artery stenosis 


\section{References}

${ }_{1}$ Klahr S, Levey AS, Beck GJ et al. The effects of dietary protein restriction and blood-pressure control on the progression of chronic renal disease. Modification of Diet in Renal Disease Study Group. N Engl J Med 1994;330:877-884

-2 Wright JT, Jr., Bakris G, Greene T et al. Effect of blood pressure lowering and antihypertensive drug class on progression of hypertensive kidney disease: results from the AASK trial. JAMA 2002;288:2421-2431

- 3 Peterson JC, Adler S, Burkart JM et al. Blood pressure control, proteinuria, and the progression of renal disease. The Modification of Diet in Renal Disease Study. Ann Intern Med 1995;123:754-762

4 Sarnak MJ, Greene T, Wang X et al. The effect of a lower target blood pressure on the progression of kidney disease: long-term follow-up of the modification of diet in renal disease study. Ann Intern Med 2005;142:342-351

5 Wuhl E, Trivelli A, Picca S et al. Strict blood-pressure control and progression of renal failure in children. N Engl J Med 2009;361:1639-1650

-6 Jafar TH, Schmid CH, Stark PC et al. The rate of progression of renal disease may not be slower in women compared with men: a patientlevel meta-analysis. Nephrol Dial Transplant 2003;18:2047-2053

7 Pohl MA, Blumenthal S, Cordonnier DJ et al. Independent and additive impact of blood pressure control and angiotensin II receptor blockade on renal outcomes in the Irbesartan Diabetic Nephropathy Trial: Clinical implications and limitations. J Am Soc Nephrol 2005; 16:3027-3037

8 Sleight P, Redon J, Verdecchia P et al. Prognostic value of blood pressure in patients with high vascular risk in the Ongoing Telmisartan Alone and in combination with Ramipril Global Endpoint Trial study. J Hypertens 2009;27:1360-1369

-9 Cushman WC, Evans GW, Byington RP et al. Effects of intensive blood-pressure control in type 2 diabetes mellitus. N Engl J Med 2010;362:1575-1585

10 Li PK, Weening JJ, Dirks J et al. A report with consensus statements of the International Society of Nephrology 2004 Consensus Workshop on Prevention of Progression of Renal Disease, Hong Kong, June 29, 2004. Kidney Int Suppl 2005;94:S2-S7

11 Lewis JB. Blood pressure control in chronic kidney disease: is less really more? J Am Soc Nephrol 2010;21:1086-1092

12 Lewis EJ, Hunsicker LG, Bain RP, Rohde RD. The effect of angiotensinconverting-enzyme inhibition on diabetic nephropathy. N Engl J Med 1993;329:1456-1462

13 Gruppo Italiano di Studi Epidemiologici in Nefrologia (GISEN): Randomised placebo-controlled trial of effect of ramipril on decline in glomerular filtration rate and risk of terminal renal failure in proteinuric, non-diabetic nephropathy. Lancet 1997;349:1857-1863

14 Ruggenenti P, Perna A, Gherardi G et al. Renoprotective properties of ACE-inhibition in non-diabetic nephropathies with non-nephrotic proteinuria. Lancet 1999;354:359-364

15 Wright JT, Jr., Bakris G, Greene T et al. Effect of blood pressure lowering and antihypertensive drug class on progression of hypertensive kidney disease: results from the AASK trial. JAMA 2002;288:2421-2431

16 Hou FF, Zhang X, Zhang GH et al. Efficacy and safety of benazepril for advanced chronic renal insufficiency. N Eng J Med 2006;354:131-140

17 Jafar TH, Schmid CH, Landa M et al. Angiotensin-converting enzyme inhibitors and progression of nondiabetic renal disease. A metaanalysis of patient-level data. Ann Int Med 2001;135:73-87

18 Brenner BM, Cooper ME, de Zeeuw D et al. Effects of losartan on renal and cardiovascular outcomes in patients with type 2 diabetes and nephropathy. New Engl J Med 2001;345:861-869

19 Lewis EJ, Hunsicker LG, Clarke WR et al. Renoprotective effect of the angiotensin-receptor antagonist irbesartan in patients with nephropathy due to type 2 diabetes. New Engl J Med 2001;345:851-860

20 Strippoli GFM, Craig M, Deeks JJ et al. Effects of angiotensin converting enzyme inhibitors and angiotensin II receptor antagonists on mortality and renal outcomes in diabetic nephropathy: systematic review. BMJ 2004;329:828-831
-21 Barnett AH, Bain SC, Bouter P et al. Angiotensin-receptor blockade versus converting-enzyme inhibition in type 2 diabetes and nephropathy. New Engl J Med 2004;351:1952-1961

22 Mann JF, Schmieder RE, McQueen M et al. Renal outcomes with telmisartan, ramipril, or both, in people at high vascular risk (the ONTARGET study): a multicentre, randomised, double-blind, controlled trial. Lancet 2008;372:547-553

23 The HOPE Study Investigators. Effects of an angiotensin-convertingenzyme inhibitor, ramipril on cardiovascular events in high-risk patients. N Engl J Med 2000;342:145-153

24 Fox KM. Efficacy of perindopril in reduction of cardiovascular events among patients with stable coronary artery disease: randomised, double-blind, placebo-controlled, multicentre trial (the EUROPA study). Lancet 2003;362:782-788

25 Braunwald E, Domanski MJ, Fowler SE et al. Angiotensin-convertingenzyme inhibition in stable coronary artery disease. New Engl J Med 2004;351:2058-2068

-26 Solomon SD, Rice MM, K AJ et al. Renal function and effectiveness of angiotensin-converting enzyme inhibitor therapy in patients with chronic stable coronary disease in the Prevention of Events with ACE inhibition (PEACE) trial. Circulation 2006;114:26-31

-27 Editors. Retraction-Combination treatment of angiotensin-II receptor blocker and angiotensin-converting-enzyme inhibitor in non-diabetic renal disease (COOPERATE): a randomised controlled trial. Lancet 2009;374:1226

28 Kunz R, Friedrich C, Wolbers M, Mann JF. Meta-analysis: effect of monotherapy and combination therapy with inhibitors of the renin angiotensin system on proteinuria in renal disease. Ann Intern Med 2008;148:30-48

29 Chronic Kidney Disease Prognosis Consortium. Association of estimated glomerular filtration rate and albuminuria with all-cause and cardiovascular mortality in general population cohorts: a collaborative meta-analysis. Lancet 2010;375:2073-2081

- 30 Jafar TH, Stark PC, Schmid CH et al. Progression of chronic kidney disease: the role of blood pressure control, proteinuria, and angiotensin-converting enzyme inhibition: a patient-level meta-analysis. Ann Intern Med 2003;139:244-252

- 31 Sleight P, Redon J, Verdecchia P et al. Prognostic value of blood pressure in patients with high vascular risk in the Ongoing Telmisartan Alone and in combination with Ramipril Global Endpoint Trial study. J Hypertens 2009;27:1360-1369

- 32 Lea J, Greene T, Hebert L et al. The relationship between magnitude of proteinuria reduction and risk of end-stage renal disease. Arch Intern Med 2005;165:947-953

33 Atkins RC, Briganti EM, Lewis JB et al. Proteinuria reduction and progression to renal failure in patients with type 2 diabetes mellitus and overt nephropathy. Am J Kidney Dis 2005;45:281-287

- 34 Eijkelkamp WBA, Zhang Z, Remuzzi G et al. Albuminuria is a target for renoprotective therapy independent from blood pressure in patients with type 2 diabetic nephropathy: post hoc analysis from the reduction in endpoints in NIDDM with the angiotensin II antagonist losartan (RENAAL) trial. J Am Soc Nephrol 2007;18:1540-1546

- 35 Hou FF, Xie D, Zhang X et al. Renoprotection of Optimal Antiproteinuric Doses (ROAD) Study: a randomized controlled study of benazepril and losartan in chronic renal insufficiency. J Am Soc Nephrol. 2007;18:1889-1898

- 36 Ruggenenti P, Cravedi P, Remuzzi G. The RAAS in the pathogenesis and treatment of diabetic nephropathy. Nat Rev Nephrol 2010;6: 319-330

- 37 The A.C.E. Inhibitors in Diabetic Nephropathy Trialist Group. Should all patients with type 1 diabetes mellitus and microalbuminuria receive angiotensin-converting enzyme inhibitors? A meta-analysis of individual patient data. Ann Int Med 2001;134:370-379

- 38 Sano T, Kawamura T, Matsumae $\mathrm{H}$ et al. Effects of long-term enalapril treatment on persistent micro-albuminuria in well-controlled 
hypertensive and normotensive NIDDM patients. Diabetes Care 1994; $17: 420-424$

- 39 Trevisan R, Tiengo A. Effect of low-dose ramipril on microalbuminuria in normotensive or mild hypertensive non-insulin-dependent diabetic patients. North-East Italy Microalbuminuria Study Group. Am J Hypertension 1995;8:876-883

-40 Agardh CD, Garcia-Puig J, Charbonnel B et al. Greater reduction of urinary albumin excretion in hypertensive type II diabetic patients with incipient nephropathy by lisinopril than by nifedipine. J Hum Hypertens 1996;10:185-192

41 Ahmad J, Siddiqui MA, Ahmad H. Effective postponement of diabetic nephropathy with enalapril in normotensive type 2 diabetic patients with microalbuminuria. Diabetes Care 1997;20:1576-1581

-42 The HOPE Study Investigators. Effects of ramipril on cardiovascular and microvascular outcomes in people with diabetes mellitus: results of the HOPE study and MICRO-HOPE substudy. Lancet 2000;355: 253-259

43 UK Prospective Diabetes Study Group. Efficacy of atenolol and captopril in reducing risk of macrovascular and microvascular complications in type 2 diabetes: UKPDS 39. BMJ 1998;317:713-720

44 Parving HH, Lehnert H, Brochner-Mortensen J et al. The effect of irbesartan on the development of diabetic nephropathy in patients with type 2 diabetes. New Engl J Med 2001;345:870-878

-45 Strippoli GFM, Craig M, Deeks JJ et al. Effects of angiotensin converting enzyme inhibitors and angiotensin II receptor antagonists on mortality and renal outcomes in diabetic nephropathy: systematic review. BMJ 2004;329:828-831

46 Rossing K, Schjoedt KJ, Jensen BR et al. Enhanced renoprotective effects of ultrahigh doses of irbesartan in patients with type 2 diabetes and microalbuminuria. Kidney Int 2005;68:1190-1198

-47 Anonymous. Randomised placebo-controlled trial of lisinopril in normotensive patients with insulin-dependent diabetes and normoalbuminuria or microalbuminuria. The EUCLID Study Group. Lancet 1997;349:1787-1792

-48 Bilous R, Chaturvedi N, Sjolie AK et al. Effect of candesartan on microalbuminuria and albumin excretion rate in diabetes: three randomized trials. Ann Intern Med 2009;151:11-20, W13-14

- 49 Mauer M, Zinman B, Gardiner R et al. Renal and retinal effects of enalapril and losartan in type 1 diabetes. N Engl J Med 2009;361:40-51

-50 Ruggenenti P, Fassi A, Ilieva AP et al. Preventing microalbuminuria in type 2 diabetes. New Engl J Med 2004;351:1941-1951

51 Haller H, Januszewicz A, Mimran A et al. Prevention of microalbuminuria in type 2 diabetes (ROADMAP Trial). European Renal Association Meeting, Munich 2010:OM005

52 Baba S. Nifedipine and enalapril equally reduce the progression of nephropathy in hypertensive type 2 diabetics. Diabetes Res Clin Pract 2001;54:191-201

53 The Diabetes Control and Complications (DCCT) Research Group. The effect of intensive treatment of diabetes on the development and progression of long-term complications in insulin-dependent diabetes mellitus. N Engl J Med 1993;329:977-986

54 UK Prospective Diabetes Study (UKPDS) Group. Intensive bloodglucose control with sulphonylureas or insulin compared with conventional treatment and risk of complications in patients with type 2 diabetes (UKPDS 33). Lancet 1998;352:837-853

55 Holman RR, Paul SK, Bethel MA et al. 10-year follow-up of intensive glucose control in type 2 diabetes. N Engl J Med 2008;359:1577-1589

56 Feldt-Rasmussen B, Mathiesen ER, Deckert T. Effect of two years of strict metabolic control on progression of incipient nephropathy in insulin-dependent diabetes. Lancet 1986;2:1300-1304

57 Reichard P, Nilsson BY, Rosenqvist U. The effect of long-term intensified insulin treatment on the development of microvascular complications of diabetes mellitus. New Engl J Med 1993;329:304-309

- 58 Bangstad HJ, Osterby R, Dahl-Jorgensen K et al. Improvement of blood glucose control in IDDM patients retards the progression of morphological changes in early diabetic nephropathy. Diabetologia 1994;37: 483-490
59 Anonymous. Intensive therapy and progression to clinical albuminuria in patients with insulin dependent diabetes mellitus and microalbuminuria. Microalbuminuria Collaborative Study Group, United Kingdom. BMJ 1995;311:973-977

-60 The Diabetes Control and Complications (DCCT) Research Group. Effect of intensive therapy on the development and progression of diabetic nephropathy in the Diabetes Control and Complications Trial. Kidney Int 1995;47:1703-1720

61 Fioretto P, Steffes MW, Sutherland DE et al. Reversal of lesions of diabetic nephropathy after pancreas transplantation. New Engl J Med 1998;339:69-75

62 Societies JB. JBS2: Joint British Societies' guidelines on prevention of cardiovascular disease in clinical practice. Heart 2005;91(Suppl V): v1-v52

63 Gerstein HC, Miller ME, Byington RP et al. Effects of intensive glucose lowering in type 2 diabetes. N Engl J Med 2008;358:2545-2559

64 Patel A, MacMahon S, Chalmers J et al. Intensive blood glucose control and vascular outcomes in patients with type 2 diabetes. N Engl J Med 2008;358:2560-2572

65 Hallan SI, Dahl K, Oien CM et al. Screening strategies for chronic kidney disease in the general population: follow-up of cross sectional health survey. BMJ 2006;333:1047

66 Weiner DE, Tighiouart H, Elsayed EF et al. The Framingham predictive instrument in chronic kidney disease. J Am Coll Cardiol 2007;50:217224

-67 Hippisley-Cox J, Coupland C, Vinogradova Y et al. Predicting cardiovascular risk in England and Wales: prospective derivation and validation of QRISK2. Bmj 2008;336:1475-1482

68 Matsushita K, van der Velde M, Astor BC et al. Association of estimated glomerular filtration rate and albuminuria with all-cause and cardiovascular mortality in general population cohorts: a collaborative meta-analysis. Lancet 2010;375:2073-2081

69 Gaede P, Vedel P, Larsen N et al. Multifactorial intervention and cardiovascular disease in patients with type 2 diabetes. New Engl J Med 2003;348:383-393

70 Gaede P, Lund-Andersen H, Parving HH, Pedersen O. Effect of a multifactorial intervention on mortality in type 2 diabetes. $\mathrm{N}$ Engl J Med 2008;358:580-591

-71 Fellstrom BC, Jardine AG, Schmieder RE et al. Rosuvastatin and cardiovascular events in patients undergoing hemodialysis. N Engl J Med 2009;360:1395-1407

72 Wanner C, Krane V, Marz W et al. Atorvastatin in patients with type 2 diabetes mellitus undergoing hemodialysis. N Engl J Med 2005;353: 238-248

73 Heart Protection Study Investigators. MRC/BHF Heart Protection Study of cholesterol lowering with simvastatin in 20,536 high-risk individuals: a randomised placebo-controlled trial. Lancet 2002;360: $7-22$

74 Navaneethan SD, Pansini F, Perkovic V et al. HMG CoA reductase inhibitors (statins) for people with chronic kidney disease not requiring dialysis. Cochrane Database Syst Rev 2009;15:CD007784

75 Go AS, Chertow GM, Fan D, McCulloch CE, Hsu C-y. Chronic kidney disease and the risks of death, cardiovascular events, and hospitalization. N Engl J Med 2004;351:1296-305

-76 Tonelli M, Jose P, Curhan G et al. Proteinuria, impaired kidney function, and adverse outcomes in people with coronary disease: analysis of a previously conducted randomised trial. BMJ 2006;332: 1426

77 Baigent C, Keech A, Kearney PM et al. Efficacy and safety of cholesterol-lowering treatment: prospective meta-analysis of data from 90,056 participants in 14 randomised trials of statins. Lancet 2005; 366:1267-1278

78 Joint British Societies. JBS2: Joint British Societies' guidelines on prevention of cardiovascular disease in clinical practice. Heart 2005; 91(Suppl 5):v1-v52

79 Cooper A, Nherera L, Calvert $\mathrm{N}$ et al. 2008. Clinical guidelines and evidence review for lipid modification: cardiovascular risk assessment 
and the primary and secondary prevention of cardiovascular disease. London: National Collaborating Centre for Primary Care and Royal College of General Practitioners. (Updated 2010) Available at: guidance.nice.org.uk/CG67/Guidance/pdf/English (Accessed 1st August 2010)

-80 Strippoli GF, Navaneethan SD, Johnson DW et al. Effects of statins in patients with chronic kidney disease: meta-analysis and metaregression of randomised controlled trials. BMJ 2008;336:645-651

81 Shepherd J, Kastelein JJP, Bittner V et al. Intensive lipid lowering with atorvastatin in patients with coronary heart disease and chronic kidney disease: the TNT (Treating to New Targets) study. J Am Coll Cardiol 2008;51:1448-1454

82 Kendrick J, Shlipak MG, Targher G, Cook T, Lindenfield J, Chonchol M. Effect of lovastatin on primary prevention of cardiovascular events in mild CKD and kidney loss: a post hoc analysis of the Air Force/Texas Coronary Atherosclerosis Prevention Study. Am J Kidney Dis 2010;55:42-49

83 Fellstrom BC, Jardine AG, Schmieder RE et al. Rosuvastatin and cardiovascular events in patients undergoing hemodialysis. N Engl J Med 2009;360:1395-1407

84 Holdaas H, Fellstrom B, Jardine AG et al. Effect of fluvastatin on cardiac outcomes in renal transplant recipients: a multi-centre, randomised, placebo-controlled trial. Lancet 2003;361:2024-2031

- 85 Deighan CJ, Caslake MJ, McConnell M, Boulton-Jones JM, Packard CJ. Atherogenic lipoprotein phenotype in end-stage renal failure: origin and extent of small dense low-density lipoprotein formation. Am J Kidney Dis 2000;35:852-862

86 Baigent C, Landry M. Study of heart and renal protection (SHARP). Kidney Int 2003;Suppl 84:S207-S210

87 Woodward M, Brindle P, Tunstall-Pedoe H. Adding social deprivation and family history to cardiovascular risk assessment: the ASSIGN score from the Scottish Heart Health Extended Cohort (SHHEC). Heart 2007;93:172-176

88 Collins GS, Altman DG. An independent and external validation of QRISK2 cardiovascular disease risk score: a prospective open cohort study. BMJ 2010;340:c2442

89 Bleyer AJ, Shemanski LR, Burke GL et al. Tobacco, hypertension, and vascular disease: risk factors for renal functional decline in an older population. Kidney Int 2000;57:2072-2079

90 Halimi JM, Giraudeau B, Vol S et al. Effects of current smoking and smoking discontinuation on renal function and proteinuria in the general population. Kidney Int 2000;58:1285-1292

91 Pinto-Sietsma SJ, Mulder J, Janssen WM et al. Smoking is related to albuminuria and abnormal renal function in nondiabetic persons. Ann Int Med 2000;133:585-591

-92 Hallan S, de Mutsert R, Carlsen S et al. Obesity, smoking, and physical inactivity as risk factors for CKD: are men more vulnerable? Am J Kidney Dis 2006;47:396-405

-93 Shankar A, Klein R, Klein BE. The association among smoking, heavy drinking, and chronic kidney disease. Am J Epidemiol 2006;164:263271

94 Regalado M, Yang S, Wesson DE. Cigarette smoking is associated with augmented progression of renal insufficiency in severe essential hypertension. Am J Kidney Dis 2000;35:687-694

95 Chase HP, Garg SK, Marshall G et al. Cigarette smoking increases the risk of albuminuria among subjects with type I diabetes. JAMA 1991;265:614-617

96 Muhlhauser I, Overmann H, Bender R et al. Predictors of mortality and end-stage diabetic complications in patients with Type 1 diabetes mellitus on intensified insulin therapy. Diabetic Medicine 2000;17:727-734

97 Orth SR, Schroeder T, Ritz E, Ferrari P. Effects of smoking on renal function in patients with type 1 and type 2 diabetes mellitus. Nephrol Dial Transplantation 2005;20:2414-2419

98 De Cosmo S, Lamacchia O, Rauseo A et al. Cigarette smoking is associated with low glomerular filtration rate in male patients with type 2 diabetes. Diabetes Care 2006;29:2467-2470
99 Stengel B, Couchoud C, Cenee S, Hemon D. Age, blood pressure and smoking effects on chronic renal failure in primary glomerular nephropathies. Kidney Int 2000;57:2519-2526

100 Orth SR, Stockmann A, Conradt C et al. Smoking as a risk factor for end-stage renal failure in men with primary renal disease. Kidney Int 1998;54:926-931

101 Ward MM, Studenski S. Clinical prognostic factors in lupus nephritis. The importance of hypertension and smoking. Arch Intern Med 1992;152:2082-2088

102 Yoshida T, Takei T, Shirota S et al. Risk factors for progression in patients with early-stage chronic kidney disease in the Japanese population. Intern Med 2008;47:1859-1864

103 Schiffl H, Lang SM, Fischer R. Stopping smoking slows accelerated progression of renal failure in primary renal disease. J Nephrology 2002;15:270-274

104 Guh DP, Zhang W, Bansback N, Amarsi Z, Birmingham CL, Anis AH. The incidence of co-morbidities related to obesity and overweight: a systematic review and meta-analysis. BMC Public Health 2009;9:88

105 Pinto-Sietsma SJ, Navis G, Janssen WM, de Zeeuw D, Gans RO, de Jong PE. A central body fat distribution is related to renal function impairment even in lean subjects. Am J Kidney Dis 2003;41:733-741

106 Gelber RP, Kurth T, Kausz AT et al. Association between body mass index and CKD in apparently healthy men. Am J Kidney Dis 2005;46:871-880

107 Stengel B, Tarver CM, Powe NR et al. Lifestyle factors, obesity and the risk of chronic kidney disease. Epidemiology 2003;14:479-487

108 Evans M, Fryzek JP, Elinder CG et al. The natural history of chronic renal failure: results from an unselected, population-based, inception cohort in Sweden. Am J Kidney Dis 2005;46:863-870

109 Lea JP, Crenshaw DO, Onufrak SJ, Newsome BB, McClellan WM. Obesity, end-stage renal disease, and survival in an elderly cohort with cardiovascular disease. Obesity 2009;17:2216-2222

110 Chazot C, Gassia JP, Di Benedetto A, Cesare S, Ponce P, Marcelli D. Is there any survival advantage of obesity in Southern European haemodialysis patients? Nephrol Dial Transplant 2009;24:2871-2876

111 Navarro-Díaz M, Serra A, Romero R et al. Effect of drastic weight loss after bariatric surgery on renal parameters in extremely obese patients: long-term follow-up. J Am Soc Nephrol. 2006;17(12 Suppl 3):S213-S217

112 Agrawal V, Khan I, Rai B et al. The effect of weight loss after bariatric surgery on albuminuria. Clin Nephrol. 2008;70:194-202

113 Serra A, Granada ML, Romero R et al. The effect of bariatric surgery on adipocytokines, renal parameters and other cardiovascular risk factors in severe and very severe obesity: 1-year follow-up. Clin Nutr. 2006;25:400-408

114 Navaneethan SD, Yehnert H. Bariatric surgery and progression of chronic kidney disease. Surg Obes Relat Dis 2009;5:662-665

115 Bibbins-Domingo K, Chertow GM, Coxson PG et al. Projected effect of dietary salt reductions on future cardiovascular disease. $\mathrm{N}$ Engl J Med 2010;362:590-599

116 He FJ, MacGregor GA. A comprehensive review on salt and health and current experience of worldwide salt reduction programmes. J Hum Hypertens 2009;23:363-384

117 Joint Health Surveys Unit. An assessment of dietary sodium levels among adults (aged 19-64) in the general population, based on analysis of dietary sodium in 24 hour urine samples. London: Food Standards Agency. 2006

118 Sacks FM, Svetkey LP, Vollmer WM et al. Effects on blood pressure of reduced dietary sodium and the Dietary Approaches to Stop Hypertension (DASH) diet. N Engl J Med 2001;344:3-10

119 Vollmer WM, Sacks FM, Ard J et al. Effects of diet and sodium intake on blood pressure: subgroup analysis of the DASH-sodium trial. Ann Inetrn Med 2001;135:1019-1028

120 Jones-Burton C, Mishra SI, Fink JC et al. An in-depth review of the evidence linking dietary salt intake and progression of chronic kidney disease. Am J Nephrol 2006;26:268-275

121 Lo-Salt. www.losalt.com/BetterForYou.html Accessed 3rd August, 2010 
122 Hsu C-y, Chertow GM. Elevations of serum phosphorus and potassium in mild to moderate chronic renal insufficiency. Nephrol Dial Transplant 2002;17:1419-1425

123 Moranne O, Froissart M, Rossert J et al. Timing of onset of CKDrelated metabolic complications. J Am Soc Nephrol 2009;20:164-167

124 Weir MR, Rolfe M. Potassium homeostasis and renin-angiotensinaldosterone system inhibitors. Clin J Am Soc Nephrol 2010;5:531-548

- 125 Nyirenda MJ, Tang JI, Padfield PL, Seckl JR. Hyperkalaemia. BMJ 2009;339:b4114

126 Covic A, Kothawala P, Bernal M, Robbins S, Chalian A, Goldsmith D. Systematic review of the evidence underlying the association between mineral metabolism disturbances and risk of all-cause mortality, cardiovascular mortality and cardiovascular events in chronic kidney disease. Nephrol Dial Transplant 2009;24:1506-1523

127 Sullivan CM, Leon JB, Sehgal AR. Phosphorus-containing food additives and the accuracy of nutrient databases: implications for renal patients J Ren Nutr 2007;17:350-354

128 Savica V, Calo LA, Monardo P et al. Salivary phosphorus and phosphate content of beverages: implications for the treatment of uremic hyperphosphatemia. J Ren Nutr 2009;19:69-72

129 Combe C, Aparicio M. Phosphorus and protein restriction and parathyroid function in chronic renal failure. Kidney Int 1994;46: 1381-1386

130 Shinaberger CS, Greenland S, Kopple JD et al. Is controlling phosphorus by decreasing dietary protein intake beneficial or harmful in persons with chronic kidney disease? Am J Clin Nutr 2008;88:15111518

\section{Acknowledgements}

Dr Maarten Taal wishes to declare the following potential conflicts of interest:

Travel grants:

Roche

EDTA 2006, 2007, 2008, 2009, 2010; ASN 2006

Shire Pharmaceuticals

ASN 2005, 2009, 2010

Orthobiotech

EDTA 2005; ASN 2004, 2007, 2008

Sanofi Aventis

EDTA 2004
31 Tonelli M, Pannu N, Manns B. Oral phosphate binders in patients with kidney failure. N Engl J Med 2010;362:1312-1324

132 Paffenberger RS Jr, Hyde RT, Wing AL, Lee I-M, Jung DL, Kampert JB. The association of changes in physical-activity level and other lifestyle characteristics with mortality among men. N Engl J Med 1993;328: 538-545

133 Thijssen DH, Maiorana AJ, O’Driscoll G, Cable NT, Hopman NT, Green DJ. Impact of inactivity and exercise on the vasculature in humans. Eur J Appl Physiol 2010;108:845-875

134 Coresh J, Selvin E, Stevens LA et al. Prevalence of chronic kidney disease in the United States. JAMA 2007;298:2038-2047

135 Keith DS, Nichols GA, Gullion CM, Brown JB, Smith DH. Longitudinal follow-up and outcomes among a population with chronic kidney disease in a large managed care organization. Arch Intern Med 2004;164:659-663

136 Hallan SI, Dahl K, Oien CM et al. Screening strategies for chronic kidney disease in the general population:follow-up of cross sectional health survey. BMJ 2006;333:1047

137 McClellan WM, Wasse H, McClellan AC et al. Treatment center and geographic variability in pre-ESRD care associate with increased mortality. J Am Soc Nephrol 2009;20:1078-1085

138 Hasegawa T, Bragg-Gresham JL, Yamazaki S et al. Greater first-year survival on hemodialysis in facilities in which patients are provided earlier and more frequent pre-nephrology visits. Clin J Am Soc Nephrol 2009;4:595-602

139 Taal MW, Brenner BM. Renal risk scores: progress and prospects. Kidney Int 2008;73:1216-1219

Advisory Groups:

Shire Pharmaceuticals 2006

Amgen 2008

Research grants:

A. Menarini Pharma UK, Bristol-Myers Squibb, Roche and Sanofi Aventis

Financial support as lead investigator for studies in the last 5 years:

A. Menarini Pharma UK, Genzyme and Roche

Dr Mark MacGregor has no conflicts of interest to declare 